\title{
Methods for Prediction of High-Speed Reacting Flows in Aerospace Propulsion
}

\author{
J. Philip Drummond* \\ NASA Langley Research Center, Hampton, Virginia 23681
}

DOI: $10.2514 / 1 . J 052283$

\section{Introduction}

$\mathbf{R}$ ESEARCH to develop high-speed airbreathing aerospace propulsion systems was underway in the late 1950s. A major part of the effort involved the supersonic combustion ramjet, or scramjet, engine. Work had also begun to develop computational techniques for solving the equations governing the flow through a scramjet engine. However, scramjet technology and the computational methods to assist in its evolution would remain apart for another decade. The principal barrier was that the computational methods needed for engine evolution lacked the computer technology required for solving the discrete equations resulting from the numerical methods. Even today, computer resources remain a major pacing item in overcoming this barrier. Significant advances have been made over the past 35 years, however, in modeling the supersonic chemically reacting flow in a scramjet combustor. To see how scramjet development and the required computational tools finally merged, we briefly trace the evolution of the technology in both areas.

We begin with a review of the history of efforts to model the scramjet environment and then concentrate on more recent activities that lead to today's computational capabilities. The National AeroSpace Plane (NASP) technology program provided strong motivation for advancing the computational capabilities of the country in both the government and private sectors. Required ground test facilities with sufficient test times were limited to around Mach 8, and higher Mach numbers, achievable in pulse facilities, could only be maintained for the order of milliseconds. In addition, the number of facility cycles available to parameterize a given engine flowpath were limited, and the facilities were expensive to operate. Computational capabilities were needed to fill each of these areas that existed in ground test facilities. Although the NASP program was not successful in developing a vehicle, it did spawn the development of new computational algorithms. The Hyper-X Program, beginning in 1995, revived high-speed computational research and development. A flight program is the catalyst that drives technology development and synthesizes all of the efforts into a unified tool for development of the ultimate experiment, the flight of a hypersonic vehicle. The genesis of most of the current day state-of-the-art computational tools for scramjet research and development began with the Hyper-X program. This paper attempts to cover this story from NASP and Hyper-X to the present day. We begin with a brief history of scramjet development leading up to the NASP Program. Although this paper will use the history of scramjet development as a roadmap for the evolution of computational tools, the reader interested in a more general look at the history should consult the papers by Billig [1] and Curran [2] on technology and its issues and Hallion [3] on hypersonic systems.

Following pioneering efforts of Ferri [4], Dugger [5], and Webber and MacKay [6] in the 1950s, a significant increase in research to develop scramjet engine concepts occurred in the 1960s. In 1965, the NASA Langley Research Center initiated the Hypersonic Research Engine (HRE) project to develop a high-speed air breathing technology for hypersonic cruise vehicles [7]. The goal of the HRE project was to flight test a regeneratively cooled, hydrogenfueled pylon-mounted scramjet on the X-15 research airplane and demonstrate design performance levels. The HRE did not reach the flight demonstration stage due to cancellation of the X-15 program, but the ground-based program did continue and resulted in the development and construction of two variable geometry engine models. Work with these models significantly increased the scramjet technology database to be applied in more advanced configurations.

Following completion of the HRE project, attention moved to propulsion concepts that would provide high performance when installed on a vehicle. The original concept, a pylon-mounted HRE, would have resulted in excessive levels of external drag, and so the pylon was removed, and work began to highly integrate the engine

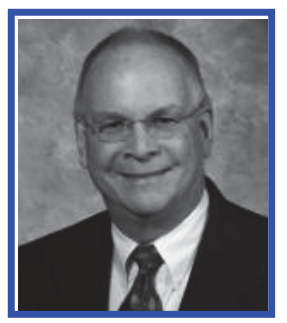

Dr. J. Philip Drummond is a Distinguished Research Associate and formerly a Senior Research Scientist in the Hypersonic Airbreathing Propulsion Branch at the NASA Langley Research Center. Previously, he served as the Head of the Combustion Group in the Theoretical Flow Physics Branch of NASA Langley Research Center, initiating the first program in computational supersonic combustion at NASA. Dr. Drummond has published over 100 papers and book chapters in the fields of combustion and propulsion. He was awarded the NASA Exceptional Service Medal for his work in high-speed turbulent combustion and hypersonic air breathing propulsion in 2004. He was also presented the Lifetime Achievement Award by JANNAF for his work in propulsion and his committee chairmanships and activities in 2011. He received the Johns Hopkins University Applied Physics Laboratory Best Technical Paper Award in 1989, the American Society of Mechanical Engineers (ASME) Best Paper Award in Propulsion in 1990, the Gene Zara Award for his contributions to the National Aero-Space Plane Program in 1989, the NASA Dual-Career Technical Excellence Award for his work in scramjet propulsion in 1994, and several NASA Special Achievement Awards over his career. He received his B.S. from the University of Virginia, M.S. from the Old Dominion University, and his Sc.D. from the George Washington University. Dr. Drummond is a Fellow of the AIAA and ASME.

Presented as Paper 2012-0112 at the AIAA Aerospace Sciences Meeting, Nashville, TN, 9-12 January 2012; received 16 August 2012; revision received 30 April 2013; accepted for publication 2 June 2013; published online 31 January 2014. This material is declared a work of the U.S. Government and is not subject to copyright protection in the United States. Copies of this paper may be made for personal or internal use, on condition that the copier pay the $\$ 10.00$ per-copy fee to the Copyright Clearance Center, Inc., 222 Rosewood Drive, Danvers, MA 01923; include the code 1533-385X/14 and \$10.00 in correspondence with the CCC.

*Distinguished Research Associate. Fellow AIAA. 
with the airframe of candidate vehicles. In addition, the engine weight was reduced by moving from a variable to fixed geometry, which reduced the engine structure. As a consequence of this activity, the Langley airframe integrated scramjet engine concept was conceived and developed. This program has continued to the present day and has resulted in the successful demonstration of the concept to produce net thrust in subscale hardware. A detailed review of this program was given by Northam and Anderson [7].

In addition to the NASA scramjet research and development program, other government activities included a Navy sponsored scramjet program at the Applied Physics Laboratory of the Johns Hopkins University (JHU/APL) [8,9]. This work also increased in the 1960s and was directed toward the development of an air-breathing shipboard missile using a scramjet propulsion system. Development of this concept continued until 1977. At that time, concern over the storage of the highly reactive and toxic fuels to be used forced a change to more conventional but safer fuels. This change resulted in the development of an integral-rocket/dual-combustor ramjet concept that used a fuel-rich gas generator to preburn the fuel for a main supersonic combustor, thus allowing the use of hydrocarbon fuels [10].

The U.S. Air Force also sponsored scramjet research and development during the 1960s [8]. They continued the support of several programs that were initially funded by the HRE program. In 1964, a program was started at the General Applied Science Laboratory to continue development of a low-speed fixed-geometry scramjet engine. A dual-mode scramjet program was continued with the Marquardt Company at the same time. Soon thereafter in 1965 , the U.S. Air Force began an effort with the United Aircraft Research Laboratory to continue development of a water cooled variable geometry scramjet design. These three efforts ended in 1968, and only the NASA and JHU/APL programs continued into the 1970s.

During the 1970s, computational techniques were first applied to study supersonic reacting flows. Research was directed at algorithm development and fundamental aspects of the flow as scramjet geometries were not yet computationally tractable. A brief summary of those activities is now given, and the reader is referred to [8] for more details. Some of the earliest work to model supersonic reacting flows was by Ferri [11] and his colleagues, Moretti [12], Edelman and Weilerstein [13], Dash [14], and Dash and DelGuidice [15]. They employed an explicit viscous characteristics method that split the governing equations into hyperbolic and parabolic parts, followed by a coupled numerical solution of each part at each integration step. Modeling multistep finite-rate chemistry was also included in their solution strategy. Spalding and his colleagues then took Ferri's splitting-based approach and improved its efficiency by developing a fully implicit solution procedure for solving the governing equations [16]. Spalding then developed several implicit parabolized NavierStokes programs for modeling scramjet combustor flowfields. These codes included the CHARNAL two-dimensional (2-D) axisymmetric code [17] and the SHIP three-dimensional (3-D) code [18]. Both codes spatially marched the governing equations in the parabolized direction while employing a tridiagonal matrix solution procedure to perform repetitive sweeps for solution of the equations in the cross plane(s) [19]. These codes assumed that a state of chemical equilibrium always existed, but they were later modified by Evans and Schexnayder [20] to include the effects of finite-rate chemical reactions. The modified codes were still being used in the early 2000s for studies of mixing and reaction in combustor configurations.

The work of Ferri [4,11] and Spalding [16-19] was then adapted by Dash to develop the SCORCH code that used a hybrid explicitimplicit procedure for modeling supersonic reacting flows. The method again split the governing equations into hyperbolic and parabolic parts. The hyperbolic part was solved using a viscous characteristics approach that employed an upwind finite difference procedure. The parabolic part was solved using an implicit finite difference procedure [21]. Work on this code and its application to supersonic combustion problems has continued to the present day.

Although Ferri [4,11], his colleagues, and Spalding [16-19] were developing analysis techniques for direct application to supersonic reacting flows, other algorithm development was underway, directed primarily at solving high-speed external flow problems. These techniques ultimately found their way into the internal reacting flow arena. The first of these algorithms was the MacCormack explicit, unsplit predictor corrector method initially developed to model the hypervelocity impact cratering problem [22]. The MacCormack method was a variation of the Lax-Wendroff second-order-accurate scheme that could be applied to complex geometries. Because of this quality, the algorithm was readily adopted and used to study a wide class of external flow problems. Implicit algorithms were also developed for external flow problems in the 1970s, motivated by the need to resolve the high gradients present in wall boundary layers. The resolution of boundary layers requires fine computational grids, resulting in a severe stability constraint on the marching time step size of an explicit method. Where only a steady-state solution was required and time accuracy was not necessary, implicit methods converged much more rapidly. Early work to develop implicit solution techniques for the Navier-Stokes equations was carried out by Briley and McDonald [23] and Beam and Warming [24]. Both approaches used a spatial factoring procedure that reduced the multidimensional problem to one of sequentially solving a set of onedimensional (1-D) spatial implicit operators. Using this computationally efficient procedure, convergence rates one to two orders of magnitude faster than the explicit method were achieved for steadystate problems on highly stretched grids.

Although the application of implicit methods was generally limited to scramjet inlet flowfields through the late 1970s and early 1980s, explicit methods were applied extensively in studies of combustor flowfields. In 1977, Drummond developed the 2-D TWODLE combustion code, based on the MacCormack method, to model internal scramjet combustor flowfields. The code used an equilibrium chemistry scheme to model $\mathrm{H}_{2}$-air reaction and algebraic eddy viscosity turbulence models. The code was applied to several scramjet combustor component problems. Particular emphasis was given to the scramjet fuel injector problem in an attempt to better understand the complex flowfield in this region of the engine $[25,26]$. Development on the code continued into the early 1980s when the code was used to carry out the first simulation of a scramjet flowfield using a 2-D model of an engine module [27]. Detailed studies to optimize the configuration of scramjet fuel injectors were also completed during this period $[28,29]$.

An explicit solution procedure was also employed by Schetz et al. during the early 1980 s to model the APL dual-combustion ramjet described earlier [30]. They employed a modular approach to carry out his analysis. The mixing and burning of the center jet from the fuel-rich gas generator was calculated with a jet mixing code [31,32] that was modified to include a turbulent kinetic energy mixing model, a chemistry model, and other improvements. Because of the high static pressures and temperatures that were present in the device, a local diffusion-controlled, equilibrium chemistry model was used to model reaction in the combustor. Schetz's procedure for modeling combustor flows was ultimately combined with an inlet analysis procedure to compute performance estimates for the dual-combustion ramjet [33].

Although numerical methods for modeling scramjet flowfields were developing through the 1960s, 1970s, and early 1980s, there was a parallel growth in computer hardware upon which these methods could be applied. Many of the early calculations were carried out on IBM 7090 and CDC 6600 class machines. Hardware improvements, which allowed the consideration of more realistic problems, came in the late 1960s with the arrival of the CDC 7600 computer. The most significant hardware improvement came in the mid to late 1970s, however, when vector processing supercomputers became available to the computational community. These machines included the CDC Star-100 and the Cray 1, followed in the early 1980s by the Cyber 205 and the Cray X-MP, which gave performance capabilities several orders of magnitude greater than the previous scalar machines [8]. Until this time, computer resources were a major limitation to advancing the state of the art for modeling supersonic reacting flows. With the Cyber 205 and Cray X-MP, however, the researcher was now in a position to begin dealing with the detailed 
physics contained in these complex flows. The burden now returned at least partially to the state of numerical algorithms used to model supersonic combustion. Later experience would show that an even greater challenge rested in the physical modeling used to describe the flow physics in high-speed propulsion systems.

\section{NASP and Early Code Development Efforts}

As previously described, only the NASA and JHU/APL hypersonic programs continued into the 1970s [34]. Both programs were limited to ground-based experimental programs and modest theoretical and computational programs to guide and analyze the experimental efforts. A new national hypersonics program was needed to spur development and the need for more advanced theoretical and computational tools. The program to develop a singlestage-to-orbit hypersonic vehicle, the NASP or X-30, shown in Fig. 1 began as a joint U.S. Air Force-NASA program in 1985. That program had actually been underway since 1982 as a highly classified Defense Advanced Research Projects Agency project called Copper Canyon [35]. Ronald Reagan, in his 1986 State of the Union Address, described the program as "a new Orient Express that could, by the end of the next decade, take off from Dulles Airport and accelerate up to twenty-five times the speed of sound, attaining low earth orbit or flying to Tokyo within two hours." Unfortunately, the goals of the Orient Express and other uses of a single-stage-to-orbit vehicle were not achieved during the program. However, the related technology programs for both an orbital and hypersonic cruise vehicle lasted for 13 years with other programs, albeit more modest or realistic, continuing to the present day.

The NASP technology program provided strong motivation for advancing the computational capabilities of the country in both the government and private sectors. As mentioned earlier, ground test facilities with sufficient test times were limited to around Mach 8, and higher Mach numbers, achievable in pulse facilities, could only be maintained for the order of milliseconds. Also, the number of cycles available to design a given engine flowpath were limited due to hardware degradation, facility availability, and expense. Computational capabilities were needed to fill in the gaps. Short-term efforts concentrated on extending existing capabilities for the simulation of high-subsonic and supersonic turbulent reacting flows.

One of the first efforts in this new hypersonic program involved extension of the TWODLE code [36] initially developed as a highspeed combustion research tool to include detailed models for finiterate chemistry and kinetic-theory-based models for the molecular diffusion of momentum, heat, and species. This extended code evolved into the SPARK combustion code used in a number of early studies of the Copper Canyon and NASP flowpaths. Carpenter and Kamath [37] extended the SPARK code to three dimensions and added generalized equilibrium chemistry and finite-rate chemistry models that allowed consideration of any fuel-air system with any number of reaction paths [38]. Three-dimensional parabolized Navier-Stokes codes were also developed to model supersonic combustor flowfields. These codes provided a more efficient solution

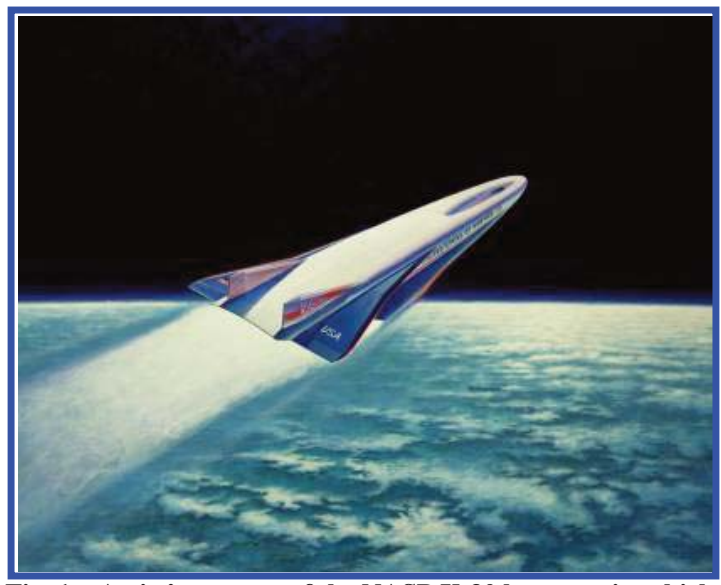

Fig. 1 Artist's concept of the NASP X-30 hypersonic vehicle. procedure if the flowfield contained no subsonic regions. Chitsomboon and Northam developed a 3-D parabolized NavierStokes (PNS) code [39] by extending a two dimensional PNS code that he had developed earlier $[40,41]$. They solved the conventional parabolized Navier-Stokes equations together with a set of species continuity equations. A new 3-D explicit upwind PNS algorithm based on Roe's flux-difference splitting was then developed by Korte and McRae [42]. The method was second-order-accurate in the marching direction as well as the cross-stream directions. The algorithm was extended by White et al. [43] to include finite-rate chemical reactions. In addition, the unsteady Riemann problem, rather than the steady Riemann problem used in the original formulation, was solved using the unsteady Riemann solver of Roe [43]. During this same period, Guilda and McRae developed a nonreacting 3-D explicit PNS code [44] using the MacCormack explicit algorithm [22]. Guilda and McRae extended their code to multiple species by adding the parabolized species continuity equations to the governing equation system [45]. They also incorporated both an equilibrium and a global one-step $\mathrm{H}_{2}$-air finiterate scheme into the code. Carpenter and Kamath then employed the Gielda algorithm to develop a parabolized version of the 3-D SPARK combustion code [37]. They generalized the coordinate transformation to allow the streamwise coordinate to be orientated in the dominant supersonic direction. They also used the generalized equilibrium and finite-rate chemistry schemes developed by Carpenter [38], and so any multistep reaction scheme could be considered with the algorithm. All of these codes were vectorized to run efficiently on available vector supercomputers of the day including the Cray 2 and the Cyber 205.

In addition to the codes extended or sponsored by NASA, the codes developed by Spalding [16-19], Dash [14,15,21], MacCormack [22], and their colleagues continued to be popular tools for modeling supersonic reacting flows in scramjet combustors. The Spalding 3-D parabolized Navier-Stokes code SHIP [18], as modified by Evans and Schexnayder [20], was still being used to carry out engineering design studies of scramjet configurations as well as basic high-speed fuel-air mixing studies. The 2-D parabolized Navier-Stokes code, SCORCH, of Dash et al. [21] saw considerable use performing analyses of the NASP propulsion system. In addition, the code was also used to carry out several fundamental studies of experiments being used to design that propulsion system.

The development of a number of new algorithms was underway in the early or mid-1980s with the majority falling into the general class of monotone methods, that is, methods that employed flux-correcting or flux-limiting procedures to preserve high numerical resolution without the numerical oscillations associated with higher accuracy. Included in this class of algorithms were flux corrected transport (FCT) methods, total variation diminishing (TVD) methods, and TVD-like methods that exhibit TVD behavior. These algorithms offered the modeler advantages over the previous methods when studying scramjet problems. Many of the codes using these algorithms were developed to model supersonic or hypersonic flow with interacting air chemistry.

The first monotone method applied to chemically reacting flows was the FCT algorithm developed by Boris $[46,47]$ and discussed by Oran [48]. Its development actually began in the 1970s and was revisited for propulsive flows in the late 1980s. In this method, the combination of a monotone low-order scheme applied in regions with high gradients was combined with a high-order scheme applied in smooth regions of the solution. As a consequence, a small amount of artificial diffusion was added to the governing equations in smooth regions of the flow to stabilize the solution. In regions where high gradients existed, larger amounts of diffusion were added to maintain monotonicity. Zalesak later generalized the approach allowing the method to be readily incorporated into existing algorithms that did not provide monotone behavior [49]. In addition, the method could be more easily generalized to two and three spatial dimensions. A more recent discussion of the method was given by Oran and Boris [50]. 
Much of the new work with monotone methods was motivated by the need to model external flows about hypersonic vehicles including NASP as well as reentry vehicles. These methods were developed to model high-speed strongly shocked flows undergoing air chemistry. To compute flows of this type, MacCormack and Candler [51-54] developed an implicit flux split scheme, as an extension to MacCormack's explicit predictor-corrector finite difference method [22], to solve the Navier-Stokes equations. MacCormack initially developed the implicit algorithm to consider only nonreacting flows [51]. A finite volume approach was used to discretize the flux terms. In addition, Steger-Warming flux vector splitting [52] was introduced to more properly account for the propagation of information through the flowfield. Following development of the basic algorithm, Candler and MacCormack extended the method to consider high-speed airflows that were ionized and in thermodynamic and chemical nonequilibrium [53,54]. Subsequent successes modeling flows with air chemistry made it apparent that the algorithms could readily be modified to consider internal flows with combustion chemistry and, therefore, serve as a means for modeling scramjet combustor flowfields.

Flux splitting methods were also employed by Grossman, Walters, and Cinnella [55-61] to model high-speed chemically reacting flow problems. Grossman and Walters initially developed their algorithm to solve the Euler equations for nonreacting flows, but included real gas effects [55]. Three forms of flux splitting were considered, including Steger-Warming flux vector splitting [52], van Leer flux vector splitting [56], and Roe flux difference splitting [57]. Each of these splitting methods was originally derived to be applied to ideal gas flows. They were rederived by Grossman and Walters [55] to allow their application to problems with real gas effects. The flux split equations were solved using a two-step predictor-corrector method that was second-order-accurate in space and time. Spatial differences were formed using the MUSCL differencing procedure and flux limiting by Anderson et al. [58]. Following the successful application of the algorithm to a 1-D shock tube problem, real gas splitting was incorporated into a 2-D implicit finite volume code that originally used van Leer splitting and Gauss-Seidel line relaxation to solve the equations governing ideal gas flows [59].

Grossman and Cinnella then extended the algorithms to include vibrational and chemical nonequilibrium $[60,61]$ by appending species continuity equations to account for each chemical species present in the reacting flow and vibrational energy conservation equations to account for those species in vibrational nonequilibrium. The authors then redeveloped the relationships described previously that were required to implement Steger-Warming, van Leer, and Roe flux splitting. Once these splitting approaches had been implemented, a finite volume scheme was used along with either an explicit Runge-Kutta time integration or an implicit Euler time integration to solve the governing equations. Nonequilibrium effects were modeled with a five-species five-reaction model that included $\mathrm{N}_{2}, \mathrm{O}_{2}, \mathrm{NO}, \mathrm{N}$, and $\mathrm{O}$. Extensions of the algorithm to two and three dimensions were then carried out.

Additional interesting work using flux splitting was also conducted by Liou et al. [62]. The authors again employed van Leer flux vector splitting or Roe flux difference splitting and derived real gas versions of these approaches. The derivations were begun by assuming a general equation of state for a real gas in equilibrium. Approaches similar to those discussed previously were then used to modify the splitting, but the number of assumptions employed were kept to a minimum. The modified splitting was then incorporated into an available TVD algorithm [63] and used to model several problems described by the 1-D Euler equations. The algorithm was then extended to two and three dimensions in the RPLUS codes to be described later in this section.

A considerable amount of work was also undertaken to develop new TVD schemes for chemically reacting real gas flows. Beginning in 1985, Yee developed a symmetric TVD scheme that could be employed in the context of either explicit or implicit numerical integration procedures [64]. The approach was later generalized to consider chemically reacting flows [65]. Yee noted that her approach could readily be added to existing algorithms that did not exhibit
TVD behavior, e.g., the 1969 MacCormack method [22], resulting in a more robust method with better shock capturing qualities. New explicit, semi-implicit, and implicit algorithms employing the symmetric TVD method were then developed and discussed [65]. An explicit multistep TVD scheme was constructed using the 1969 MacCormack method [22] for the first two (predictor-corrector) steps followed by the addition of a conservative dissipation term as a third step, such that the overall scheme was TVD. The dissipative term was made up of eigenvector products of the Jacobian matrices of the governing equation system and their associated eigenvalues, an entropy correction, and a limiter function. Details regarding the construction of the dissipative term and the determination of its magnitude is given in [66]. Finally, a fully implicit TVD method was developed including both implicit source and flux terms for situations where both chemistry and fluid scales were small and of the same order [65].

When implicit alternating-direction implicit (ADI) procedures were used, the factorization error that resulted when the implicit operator was spatially factored could not be neglected in some calculations. An alternate procedure developed by Gnoffo et al. [67] and Gnoffo and Green [68] employed point implicit relaxation. Gnoffo et al. used this procedure in their 3-D finite volume code with a symmetric TVD upwind discretization of the governing Navier-Stokes, species continuity, vibrational, and electron energy equations. Pseudotime relaxation was used to drive the solution to a steady state. This procedure proved to be very efficient on vector computers. Two options for coupling the governing fluid and chemistry equations, strong and weak implicit coupling, were also used. With strong implicit coupling, the complete equation set was solved as a unit, an approach typical of those described earlier. Weak implicit coupling involved splitting the fluid and chemistry equations into two groups and applying the point-implicit method to each group separately during the relaxation process. The former approach allowed for better accounting for complex wave interactions and fluid-kinetic coupling. The latter approach allowed for the relaxation strategy and time stepping to be tailored to the needs of the equation set [68], reducing the computational costs for some problems. Air chemistry was modeled in the code using an eleven species scheme that included $\mathrm{N}, \mathrm{O}, \mathrm{N}_{2}, \mathrm{O}_{2}, \mathrm{NO}, \mathrm{N}^{+}, \mathrm{O}^{+}, \mathrm{N}_{2}^{+}, \mathrm{O}_{2}^{+}, \mathrm{NO}^{+}$, and $e^{-}$. Further details on the chemistry model and other physical modeling are given in [69].

Another attractive alternative to an ADI integration scheme for solving the spatially discretized governing equations was a lowerupper (LU) scheme that approximately splits the implicit operator into upper and lower operators that are independent of the dimensionality of the problem. Shuen and Yoon developed a scheme for solving the 2-D Navier-Stokes and species continuity equations governing chemically reacting flows that employed an implicit finite volume time marching LU method [70]. Details of the derivation of the LU scheme are given by Shuen and Yoon [70]. The approach was attractive because, even though the method was fully implicit, it only required a scalar diagonal inversion for solution of the flow equations and a diagonal block inversion of the species equations. The authors stated that, as a result, the scheme exhibited a fast convergence rate while requiring approximately the same amount of work as an explicit method [70]. This advantage was particularly important when problems with a large number of chemical species were being solved. Following development of the RPLUS code using this technique, an eight-species 14-reaction chemistry model, an algebraic turbulence model, and later several two-equation turbulence models $[71,72]$ were added to the code. Encouraged by their success, Shuen and $\mathrm{Yu}$ extended the LU code to three dimensions (RPLUS3D) [73].

With the exception of flux corrected transport that combines a high-order and low-order method, the methods described in the preceding paragraphs have exhibited second-order numerical accuracy in both space and time. Two high-order-accurate methods were also developed and applied to high-speed combustion problems. These methods offered improved accuracy and reduced phase error. One method was developed by Carpenter and Kamath using a fourth-order compact finite difference scheme [37]. The 
scheme was initially developed by Abarbanel and Kumar to accurately solve the Euler equations in two and three dimensions [74]. Carpenter extended these ideas to the Navier-Stokes equations and used them to alter the 1969 MacCormack method [22], producing a fourth-order "compact MacCormack" scheme. The modification did not change the basic structure of the MacCormack scheme, allowing it to be easily incorporated into existing codes using the 1969 algorithm. The modification significantly improved the accuracy of the algorithm, while markedly reducing the phase error. As a result, the improved scheme was able to crisply capture strong shocks with very little of the pre- and postshock oscillations present in the old scheme. The algorithm in fact exhibited a TVD-like behavior when capturing waves.

High-order-accurate spectral methods were also applied to supersonic reacting flows. Drummond et al. extended a Chebyshev spectral method developed for studying transitioning flows [75,76] to include finite-rate chemical reactions [77]. To apply this method to the Navier-Stokes and species continuity equations, the flux terms in these equations were expanded in terms of a Chebyshev series, and then, the required spatial derivatives were taken. The resulting ordinary differential equations were then integrated with respect to time using a Runge-Kutta time stepping scheme. Drummond et al. initially developed this technique for the 1-D Euler equations and species continuity equations [77]. The method was then extended to multiple dimensions where a hybrid spectral finite difference algorithm was used to model 2-D supersonic reacting flows [78].

Many of these high-speed code development activities reached some degree of maturity toward the end of the NASP era, but much work remained. In the late 1980s and early 1990s, the NASP program began to contract, although it was sustained for several years by a technology development program. This program allowed some of the more fundamental activities that have been discussed to continue, including computational and flow diagnostic development, and flowpath research. Absent, however, was the all-important flight program that should have been underway by this time. A flight program is the catalyst that drives technology development and synthesizes all of the efforts into a unified tool for development of the ultimate experiment, the flight of a hypersonic vehicle. Hypersonics research has gone through several cycles in the United States over the past 60 years. Fortunately the NASP program was followed in the next few years by another "cycle," the Hyper-X flight program. The "run-up" to Hyper-X sustained the fundamental computational, diagnostic, and experimental programs allowing them to mature to the supporting role that was required for a successful flight program.

\section{Hyper-X and a New Generation of High-Speed Reacting Flow Codes for Scramjets}

Following more than 40 years of ground-based scramjet research and testing, a strong consensus developed in the hypersonic propulsion community for moving air-breathing technology from ground facilities to flight. Even though much had been achieved in groundbased facilities, it was impossible to duplicate the complexities of hypersonic flight without flying in the atmosphere. From this recognition, the Hyper-X Project evolved in late 1995 as a joint effort of the NASA Langley and Dryden Research Centers $[79,80]$. The program was planned to use a $12 \mathrm{ft}$ hypersonic vehicle with a scramjet propulsion system to be launched from a B-52 aircraft and accelerated to hypersonic speeds by a Pegasus rocket. The stack (the Hyper-X aircraft and the rocket) was carried under the wing of the B-52, as shown in Fig. 2.

A layout of the Hyper-X vehicle is given in Fig. 3. The vehicle was $148 \mathrm{in.} \mathrm{long}$ and $60 \mathrm{in}$. wide at the maximum extent between the tail fins. The scramjet was $30 \mathrm{in.} \mathrm{long} \mathrm{and} 19 \mathrm{in}$. wide. The vehicle was flown to around $40,000 \mathrm{ft}$ and then dropped from the carriage beneath the wing of the B-52. The Pegasus rocket was then ignited to boost the vehicle to around 95,000 ft. At that altitude, the rocket and vehicle were separated, and the scramjet engine was ignited allowing the vehicle to cruise under its own power. Two successful Hyper-X flight tests at Mach 7 and Mach 10 were flown in March and November of 2004 .

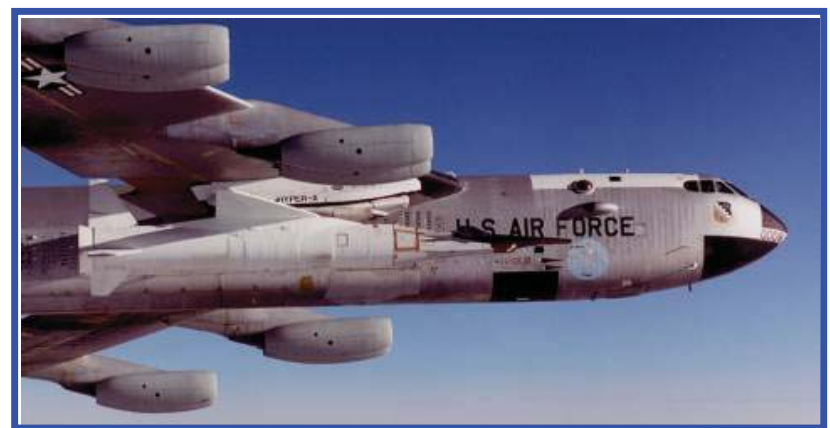

Fig. 2 Hyper-X launch stack beneath the wing of a B-52.

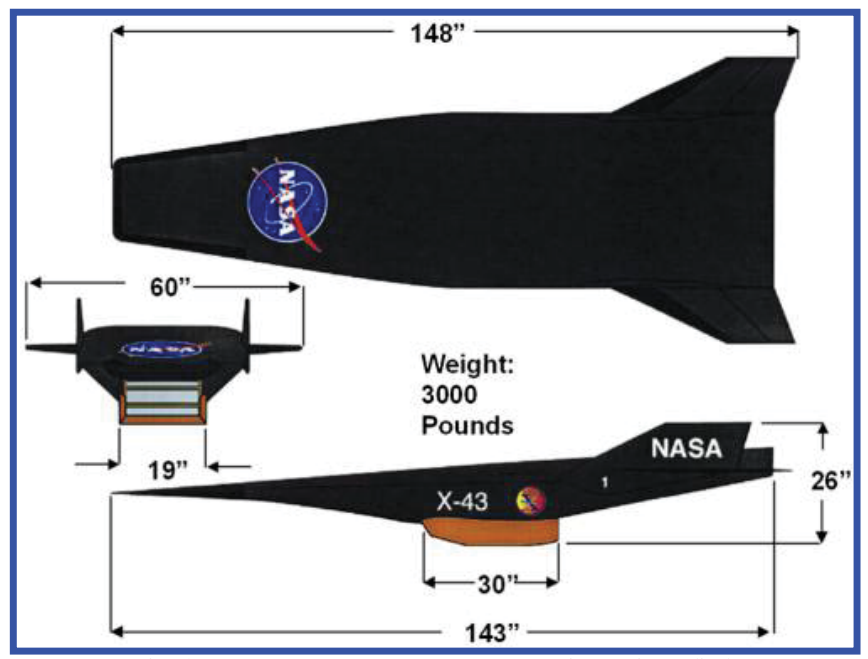

Fig. 3 Hyper-X layout and overall dimensions (in.).

The Hyper-X Program brought a resurgence of effort in hypersonics including wind-tunnel and flowpath testing and more fundamental work in measurement diagnostics, chemical kinetics, and nonreacting and reacting flow simulation and modeling. We will concentrate in this paper on the code development and modeling activities.

\section{A. Reynolds-Averaged and Large-Eddy Simulation/Reynolds- Averaged Navier-Stokes Combustion Codes}

Much of the early work associated with the Hyper-X Program was fundamental in nature. As a consequence, the development of new combustion codes tended to focus on capabilities for detailed analyses of the engine flowfield. Computer resources were still limited, but by constraining the analyses to critical regions of the scramjet, reasonable analyses were possible. Codes were developed to study the fuel injection process and the mixing and combustion of fuel and air downstream of the injectors. Detailed fuel injector design was also considered in order to enhance fuel-air mixing and enable the highest level of mixing and combustion efficiency.

Hyper-X was a flight program, however, and understanding critical regions of the engine flowfield was extremely important, but only part of the problem facing researchers. The overall engine flowpath had to be designed and that design depended on both experimental research and computational analyses. Ground-based facilities, where the experimental work was conducted, functioned in the lower Mach number range of the vehicle and were expensive to operate. Computational tools were needed to establish initial designs for testing and to fill in the regions between test points in the facilities. As a consequence, code development forked in two directions with one branch continuing along theoretical grounds and the other concentrating on the development of design codes. The development of these codes over a number of years produced many of the codes in use today for both fundamental studies and design purposes. Some of the codes in fact served both purposes. We will trace the development of these codes for the remainder of this paper. Software development that was initiated to create codes for commercial use will not be 
considered in this paper. In addition, not every code capable of simulating high-speed reacting flows will be discussed, but the author will attempt to cover every class of code that is capable of performing these analyses.

One of the first efforts to develop a code for scramjet applications began in 1987. The GASP development program resulted in a code that solved the steady and unsteady Euler, parabolized NavierStokes, thin-layer Navier-Stokes, and Navier-Stokes equations. It used as options preconditioning, approximate factorization, line Gauss-Seidel, generalized minimal residual [81], mesh sequencing, and multigrid. Inviscid flux definition in GASP used several options, including Roe's [57] and van Leer's [56] splitting with upwind biased formulations and central differencing with artificial viscosity. Central differences were used to define viscous fluxes. Both algebraic and two-equation turbulence models with wall function options were used in the code. Generalized zonal-boundary interpolation was used across zonal intersections defined by a single logical boundary. Parallel processing was employed on shared memory computer architectures. A set of thermochemical kinetic models was provided for air chemistry, hydrogen-air combustion, and various hydrocarbon reactions in a database containing 455 reactions and 34 species. Thermal nonequilibrium was modeled using a separate vibrational temperature for each molecule or a lumped vibrational temperature common to all molecules [82]. GASP was validated for a number of external and internal flowfields [83-85]. The code was then employed to analyze the external flowfields about a number of hypersonic vehicles and high-speed engine flowpaths.

Another initial effort to develop a new code for scramjet flowpath design was undertaken at the NASA Langley Research Center. The LARCK code development project began in the early 1990s as a replacement for the SPARK combustion code. The code that evolved was a cell-centered, finite volume, multiblock, multigrid code to solve the full Reynolds-averaged Navier-Stokes (RANS) equations for turbulent nonequilibrium chemically reacting flows ${ }^{\dagger}$ [86]. The code contained a generalized thermodynamics model for an arbitrary mixture of thermally perfect gases and an Arrhenius-based finite-rate chemistry model with a generalized scheme that allowed for the specification of the reaction model. Turbulence models included the Spalart-Allmaras model [87], the Wilcox high- and low-Reynoldsnumber $k-\omega$ models, Wilcox's compressible pressure gradient corrected wall matching procedure [88], Menter's baseline and supersonic transport models $[89,90]$, the $k-\epsilon$ low-Reynolds-number model of Abid [91], and the algebraic Reynolds stress models of Abid et al. [92] and Adumitroaie et al. [93]. Coupling between the turbulence and chemistry fields was also accounted for with Gaussian or beta assumed probability density functions to account for temperature variance effects on forward and backward kinetic rate coefficients in the chemistry model [94]. Turbulence effects on the species production rates were also accounted for by modeling the sum of the species variances using a multivariate assumed probability density function [95]. The LARCK code was validated against a number of 2- and 3-D unit problems such as flat plate flow [96], highMach-number compression ramp flow, and Mach 3 corner flow. It was then used to model individual scramjet component flows as well as the entire flowpath in a scramjet engine.

The LARCK code served as a predecessor for another new analysis code for high-speed flows that has become a standard for simulating external and internal flows even to the present day. A program to develop the VULCAN code began in 1996 as a part of a ramjetscramjet computational fluid dynamics (CFD) code development effort at the Wright Patterson Air Force Base. The foundation code was developed at that time under a U.S. Air Force contract. The next year, the code development effort moved to the NASA Langley Research Center, and work has continued at the center until the present day. Like its predecessor the code solved the equations governing 2- and 3-D calorically perfect or thermally perfect nonequilibrium chemically reacting flows. The code used a structuredgrid, cell-centered, finite volume, density-based method [97,98]. 2011.

${ }^{\dagger}$ Private conversation with J. A. White, NASA Langley Research Center,
Inviscid fluxes were computed to second-order accuracy using van Leer's MUSCL scheme [99] with either the flux difference split scheme of Roe [57] or the low dissipation flux split scheme of Edwards [100]. Viscous fluxes were computed to second-order accuracy using either a thin layer gradient or full gradient construction. The full spatially elliptic Euler or full Navier-Stokes equations were solved by integrating the conservative form of the unsteady equations in real or pseudotime (where only a steady-state solution is desired). Time-derivative preconditioning allowed the code to be applied to low-speed flows even though it had been primarily developed for high-speed regimes [101]. In addition, the code could solve the spatially hyperbolic Euler or parabolized Navier-Stokes equations. By using a four-level hierarchy of domain decomposition, grouping finite volume cells into blocks and blocks into regions, an entire physical domain could be discretized into a computational domain (the fourth level) for analysis.

The chemical reaction was modeled in the VULCAN code using a generalized Arrhenius-based model [98]. Any number of reactions in an overall reaction mechanism could be considered. Global reaction models were often considered where possible to reduce the number of chemical reactions and species being solved. Turbulence models used in the code included the $k-\epsilon$ and $k-\omega$ models previously used in the LARCK code as well improved turbulent kinetic energy models that were being developed in parallel with VULCAN. Interactions between the turbulence field and chemistry were modeled with an assumed beta probability density function (PDF) to account for the effects of temperature fluctuations on chemical reaction rates and a multivariate assumed beta PDF to account for the effect of species fluctuations on species production $[94,95]$. However, the statistical dependence among the scalars was not accounted for by these models.

One of the first applications of the VULCAN code was the investigation of advanced fuel injection schemes for scramjet engines. The code was used to evaluate the cold flow mixing effectiveness of two fuel injection schemes, a ramp injector, and a strut injector being considered for new scramjet designs [97]. The two injector designs are shown in Figs. 4 and 5. Helium was used as the fuel simulant. Cold flow simulations were conducted for each design. The grid system for each configuration is shown in Figs. 6 and 7. Mass fraction contours from the simulations for both configurations are shown in Figs. 8 and 9. The effects on the fuel plumes of streamwise vorticity generated along the sides of the ramps are clearly evident in the cross-stream planes. The vorticity provides large-scale stirring of the flowfield. The resulting large-scale eddies of fuel and air are then mixed across eddy boundaries by turbulent diffusion. Streamwise vorticity is generated for the ramp injectors by the "spillage" of flow from the high-pressure region above the ramps to the low-pressure region between the ramps. The situation is reversed for the strut injectors. A high-pressure region exists between the struts due to the swept leading edges driving the flow over the top
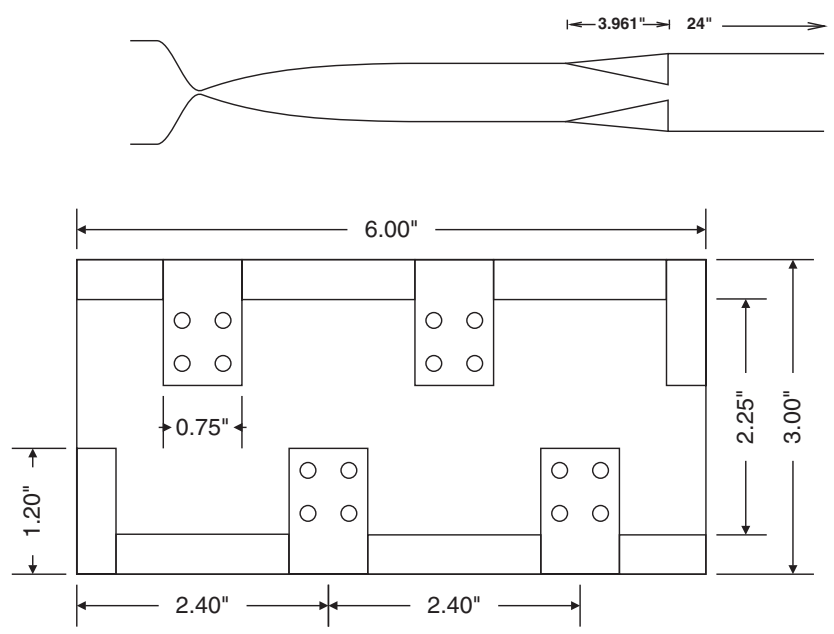

Fig. 4 Schematic of the staggered ramp injector configuration. 

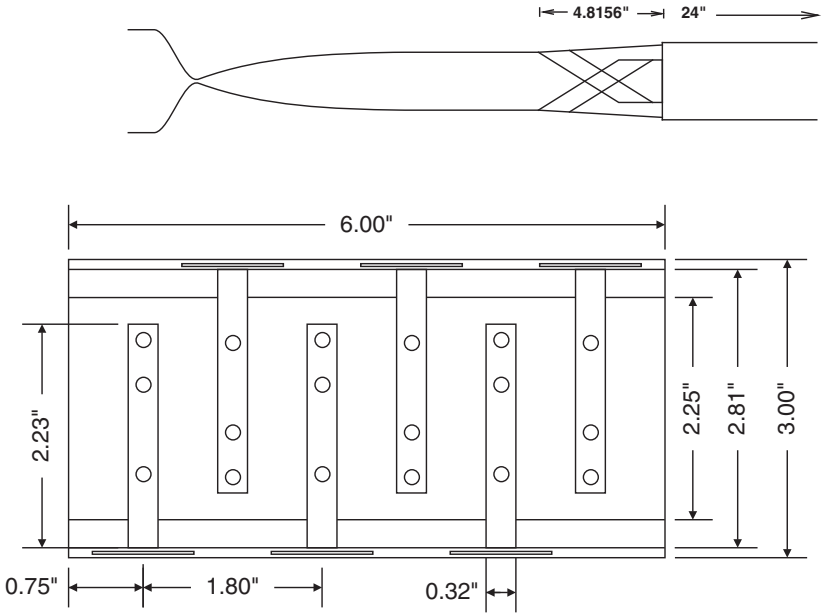

Fig. 5 Schematic of the staggered strut injector configuration.

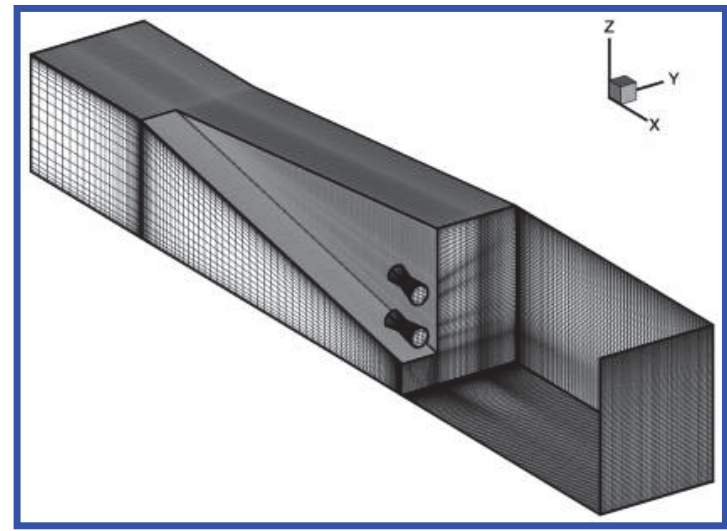

Fig. 6 Computational grid for the ramp injector configuration.

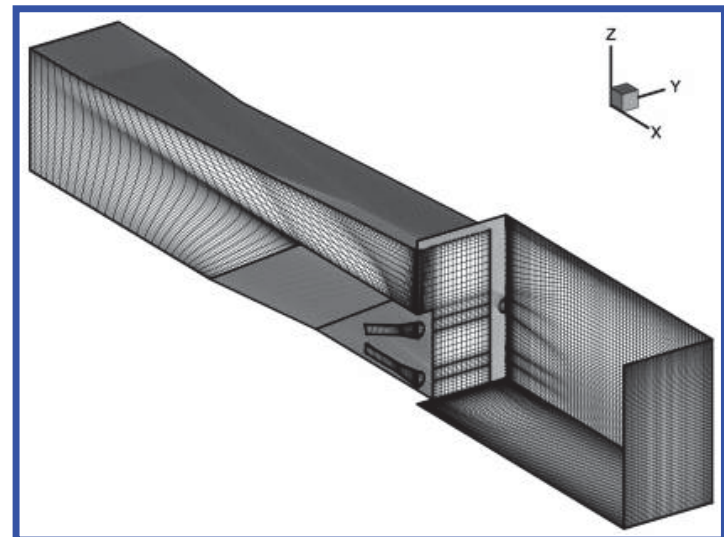

Fig. 7 Computational grid for the strut injector configuration.

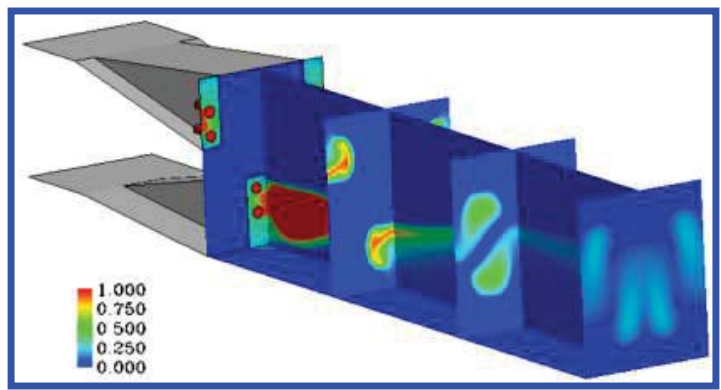

Fig. 8 Fuel mass fraction contours for the ramp injector configuration.

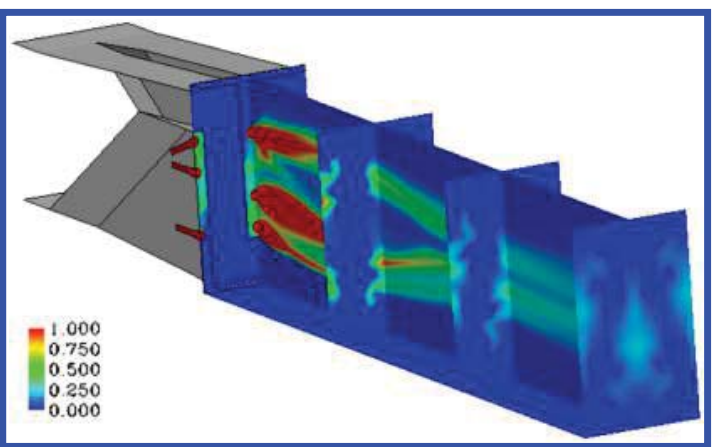

Fig. 9 Fuel mass fraction contours for the strut injector configuration.

of each strut again creating streamwise vortices. The shock structure for each configuration is illustrated in the pressure contours of Figs. 10 and 11. As can be seen, the shock structure for both designs is extremely complicated and strongly influences the fuel distribution throughout the combustor. The total pressure recovery and mixing efficiency of the two configurations is given in Fig. 12. The $x=0$ station is the fuel injection plane. The strut design initially produces more flow blockage and a higher total pressure loss. The mixing efficiency comparisons show the strut configuration significantly outperforms the ramp configuration with respect to mixing.

The VULCAN code provided a combination of advanced capabilities that had not been simultaneously available in the past. The code could efficiently incorporate the geometrically complex grids necessary to define configurations under consideration. Using domain decomposition, much finer grids could be used providing sufficient resolution of the flowfield needed to study the relevant flow physics of mixing and combustion. This approach also adapted well to parallel computing providing efficient solution of the governing equations. All of these advancements finally allowed the consideration of the real geometries of engines and their components, and the simulations provided databases from which performance "data" could be extracted. Engineers were at last provided with true guidance for engine design from numerical simulations such as the injector improvements suggested by the study that we just discussed.

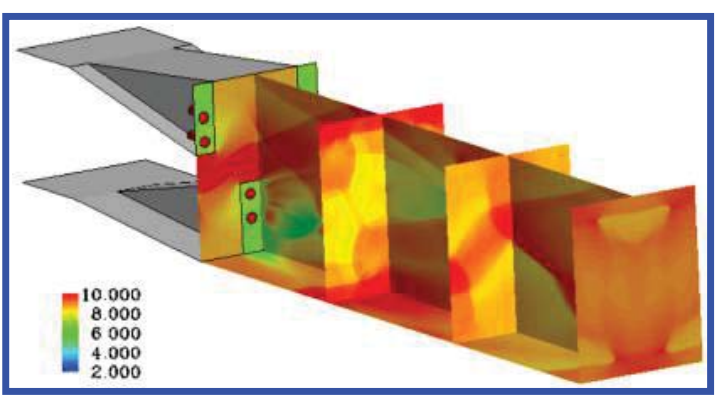

Fig. 10 Natural $\log$ of pressure contours for the ramp injector configuration.

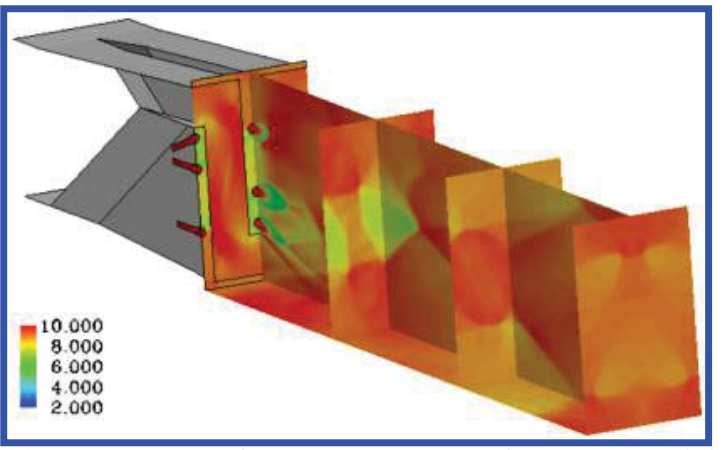

Fig. 11 Natural log of pressure contours for the strut injector configuration. 
Calculations of the type illustrated here are critically important to scramjet engine design, and they are representative of the many calculations conducted for Hyper-X. The calculations can be carried out relatively quickly and provide design data that can then be tested experimentally on the way to a final design. Arriving at the final configuration using only experimental research would be a much more costly and time consuming exercise.

Work on the VULCAN code for the past 10 years has focused on continuing algorithm improvements and the addition of large-eddy simulation (LES) capabilities, also enabling LES/RANS simulations. Steady-state Reynolds-averaged Navier-Stokes simulations with VULCAN and a number of other combustion codes have been and are currently employed for scramjet engine development. Such an

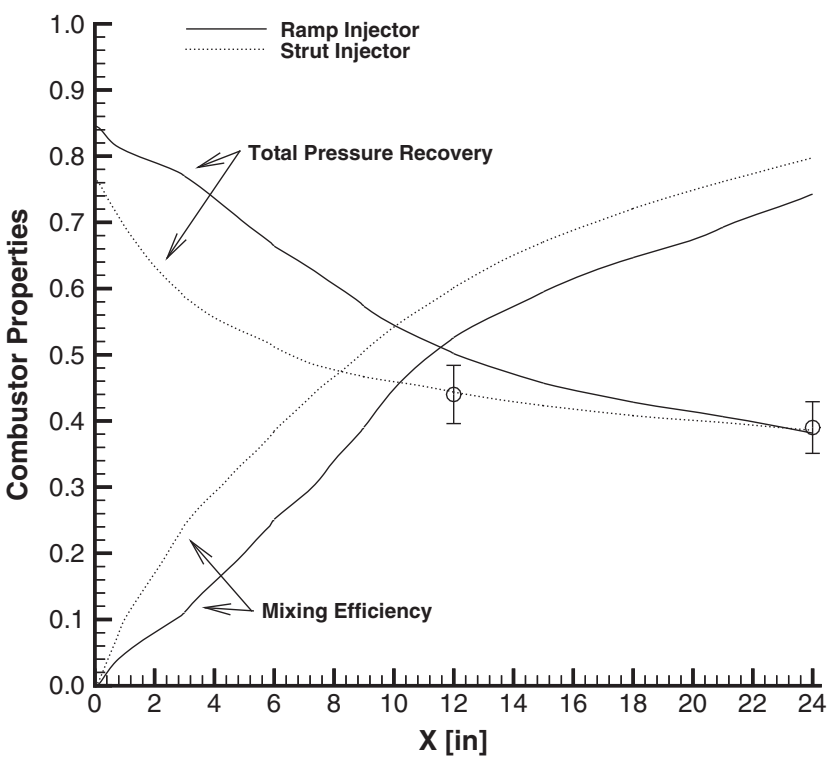

Fig. 12 Total pressure recovery and mixing efficiency comparison.
Table 1 Case 1: Helium-air test conditions

\begin{tabular}{lccc}
\hline \hline Nominal conditions & Center jet & Coflow jet & Ambient \\
\hline Mach number & $1.8^{\mathrm{a}}$ & $1.8^{\mathrm{a}}$ & $0.025^{\mathrm{b}}$ \\
Total temperature, K & $305.0( \pm 9.0)$ & $300.0( \pm 6.0)$ & $294.6( \pm 6.0)$ \\
Total pressure, $\mathrm{kPa}$ & $614.93( \pm 6.0)$ & $579.80( \pm 4.0)$ & $101.325( \pm 1.0)$
\end{tabular}

${ }^{a}$ Nozzle design Mach number.

${ }^{b}$ Value assumed for the entrained ambient flow.

Table 2 Case 2: Argon-air test conditions

\begin{tabular}{lccc}
\hline \hline Nominal conditions & Center jet & Coflow jet & Ambient \\
\hline Mach number & $1.8^{\mathrm{a}}$ & $1.8^{\mathrm{a}}$ & $0.025^{\mathrm{b}}$ \\
Total temperature, K & $297.9(3.5)$ & $294.3( \pm 3.5)$ & $294.6( \pm 3.5)$ \\
Total pressure, $\mathrm{kPa}$ & $615.86( \pm 5.5)$ & $580.68( \pm 4.4)$ & $101.325( \pm 0.6)$ \\
\hline \hline
\end{tabular}

${ }^{a}$ Nozzle design Mach number.

${ }^{b}$ Value assumed for the entrained ambient flow.

approach is not without significant limitations, however. The required turbulence and combustion models have not significantly advanced in the past 20 years, and modelers must rely on experimental data and intuition to validate these phenomenological models. An excellent review of the modeled equations that are typically solved and the models needed to close the equations was given by Baurle [102]. The limitations introduced by the models have resulted in the move to higher-order modeling including LES and PDF methods.

Scale-resolving models allow the governing equations to be solved numerically with mathematical models for only a small portion of the flow dynamics thereby reducing or alleviating many of the limitations imposed by RANS. Specifically, LES attempts to resolve the large-scale structures in a flow while only modeling the smaller scales. On the order of $90 \%$ of the transport of mass, momentum, and energy is accomplished by the large-scale eddies, and modeling is only required for the less energetic small scales. In addition, these scales are more universal in nature and, therefore, more readily modeled. But along with its stated advantages, LES is computationally expensive,

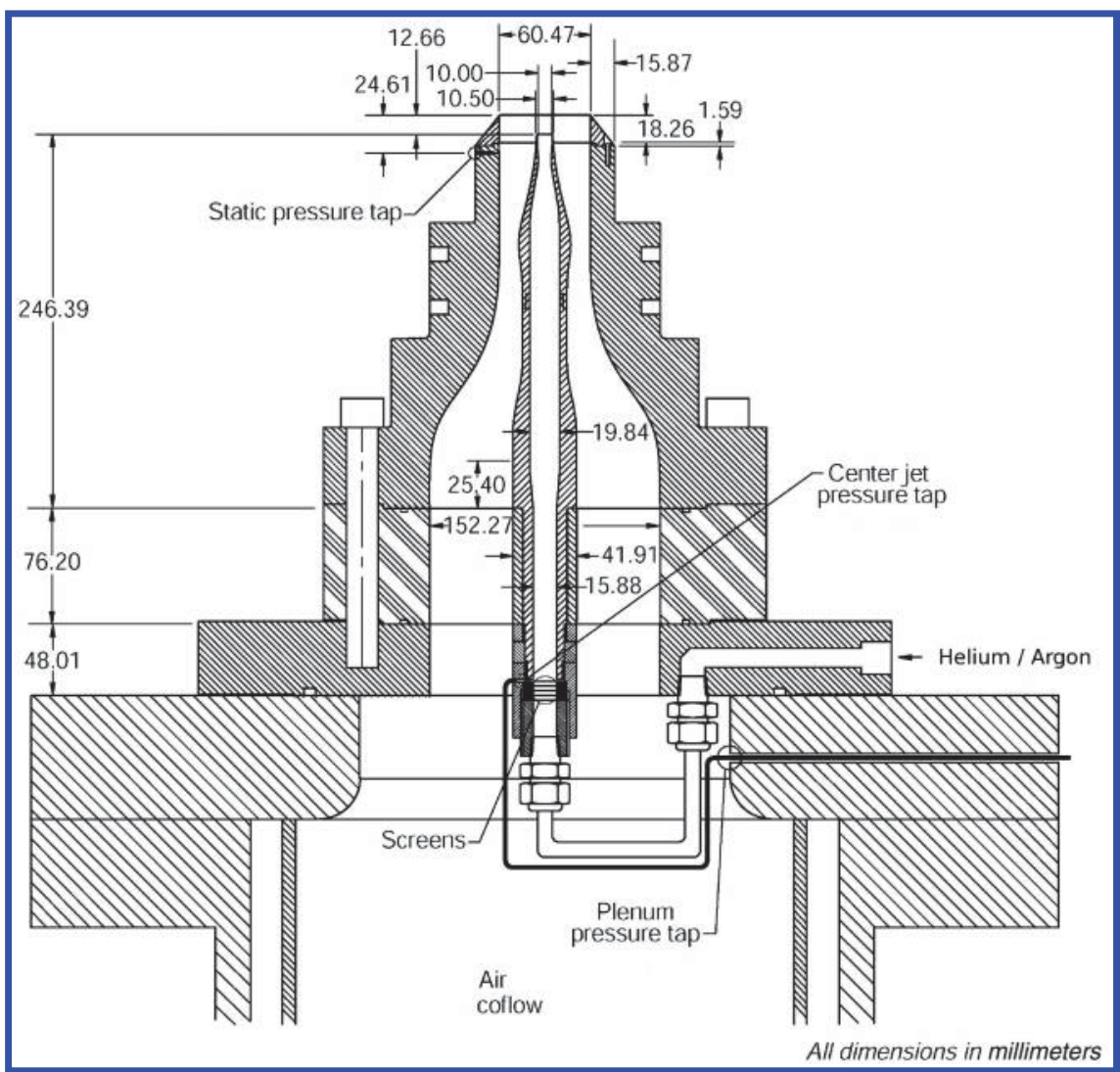

Fig. 13 Schematic of the coaxial nozzle assembly. 


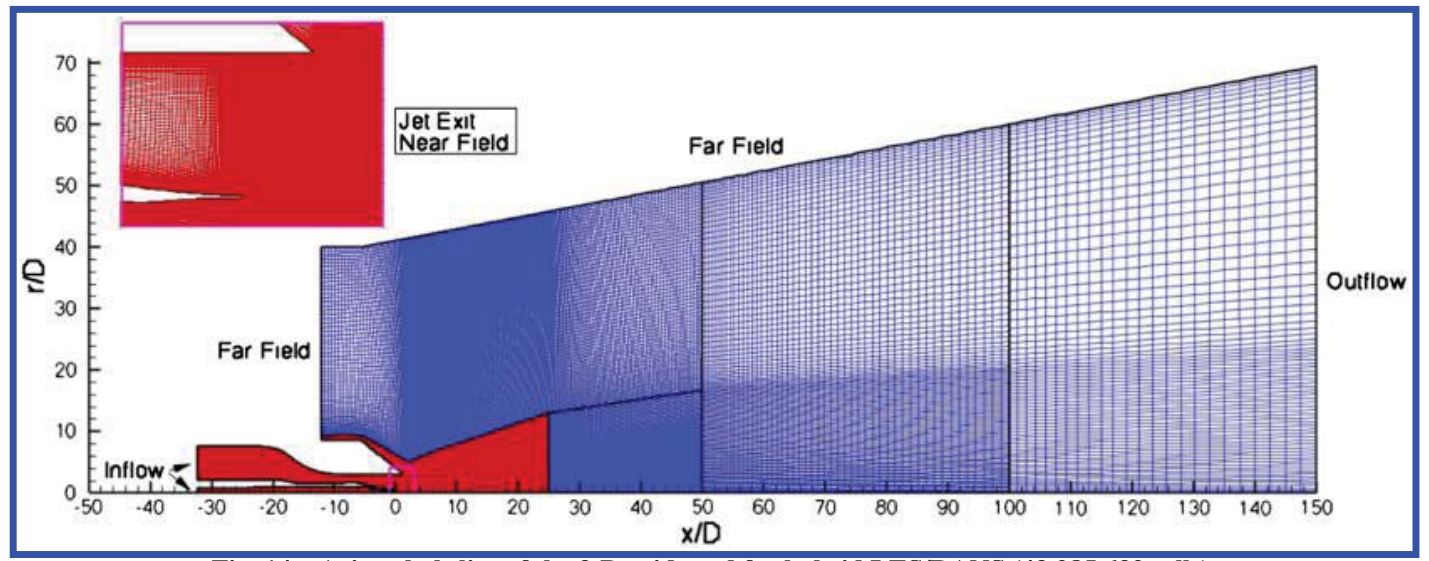

Fig. 14 Azimuthal slice of the 3-D grid used for hybrid LES/RANS (43,285,632 cells).

particularly for regions of the flowfield near walls. It is for these reasons that a hybrid method of analysis, using LES in interior flow regions of a propulsion system and RANS near engine walls, appeared so attractive.

A LES/RANS capability was added to VULCAN in the early 2000s [103]. LES/RANS analyses have been used many times since this addition was made. Major issues for the inclusion of the capability included the methods for blending the RANS and LES model equations, control of excess dissipation, and the treatment of inflow and outflow boundary conditions in the LES regions of the flow. Two methods were used to accomplish the blending of the evolving RANS and LES solutions. The first method used a strategy termed limited numerical scales, introduced by Batten et al. $[104,105]$ to blend the length-scale-velocity-scale product affecting turbulent viscosity levels and reduce the RANS stresses in LES regions of the flow. The second blending strategy used the method of detached eddy simulation proposed by Spalart et al. [106], in which the RANS-modeled equations are used near solid surfaces where the flow is attached, and the LES equations are used for separated or detached flow regimes. The original model was built around the Spalart-Allmaras one-equation model [87] with blending accomplished by altering the length scale in the destruction term of the turbulence transport equation. The detached eddy simulation approach for blending was later altered to use the two-equation $k-\omega$ model of Menter [89] using a formulation by Strelets [107]. Details regarding the blending strategy, as well as the control of dissipation and the specification of boundary conditions in LES regions, are given by Baurle et al. [103].

Several publications have resulted from LES/RANS analyses using the VULCAN code [103,108-110]. A considerable amount of work to perform LES/RANS analyses has also been conducted

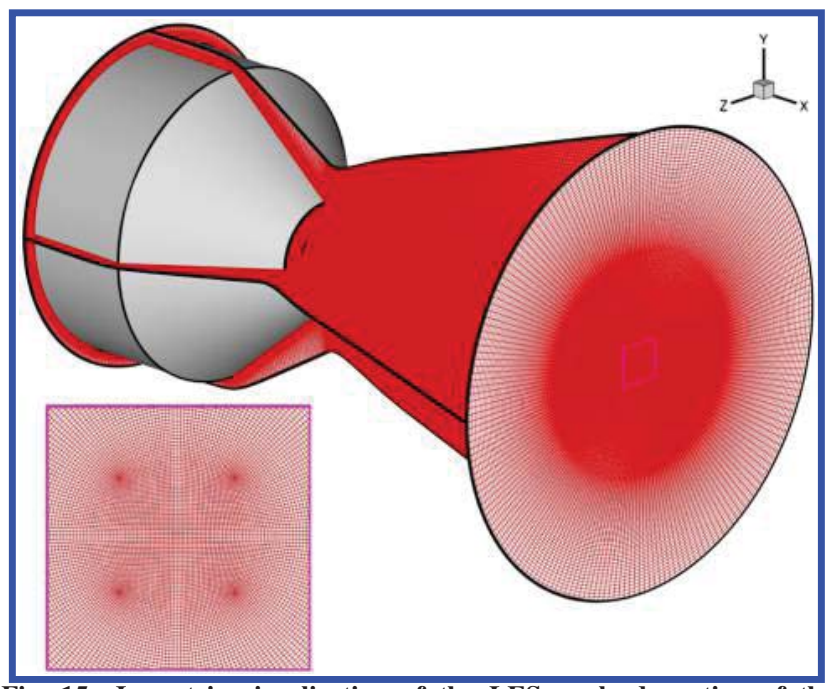

Fig. 15 Isometric visualization of the LES-resolved portion of the hybrid LES/RANS grid. with other codes [111-129]. An interesting LES/RANS simulation of a supersonic coaxial jet experiment $[130,131]$ was performed using the VULCAN code [110]. The results are typical of other LES/ RANS simulations such as those cited in the preceding references. The experiment was designed to study compressible mixing flow phenomena under conditions that are representative of those encountered in scramjet combustors. In the study, a LES/RANS simulation was compared with a RANS simulation to gather insight into the deficiencies of the Reynolds-averaged closure models. We will examine only the LES/RANS solution in this paper and leave it to [110] if the reader is interested in the comparison of the LES/RANS and RANS solutions.

A schematic of the coaxial nozzle assembly is shown in Fig. 13. The center jet flow was either a mixture of $95 \%$ helium and $5 \%$ oxygen (by volume) or pure argon. A small amount of oxygen was

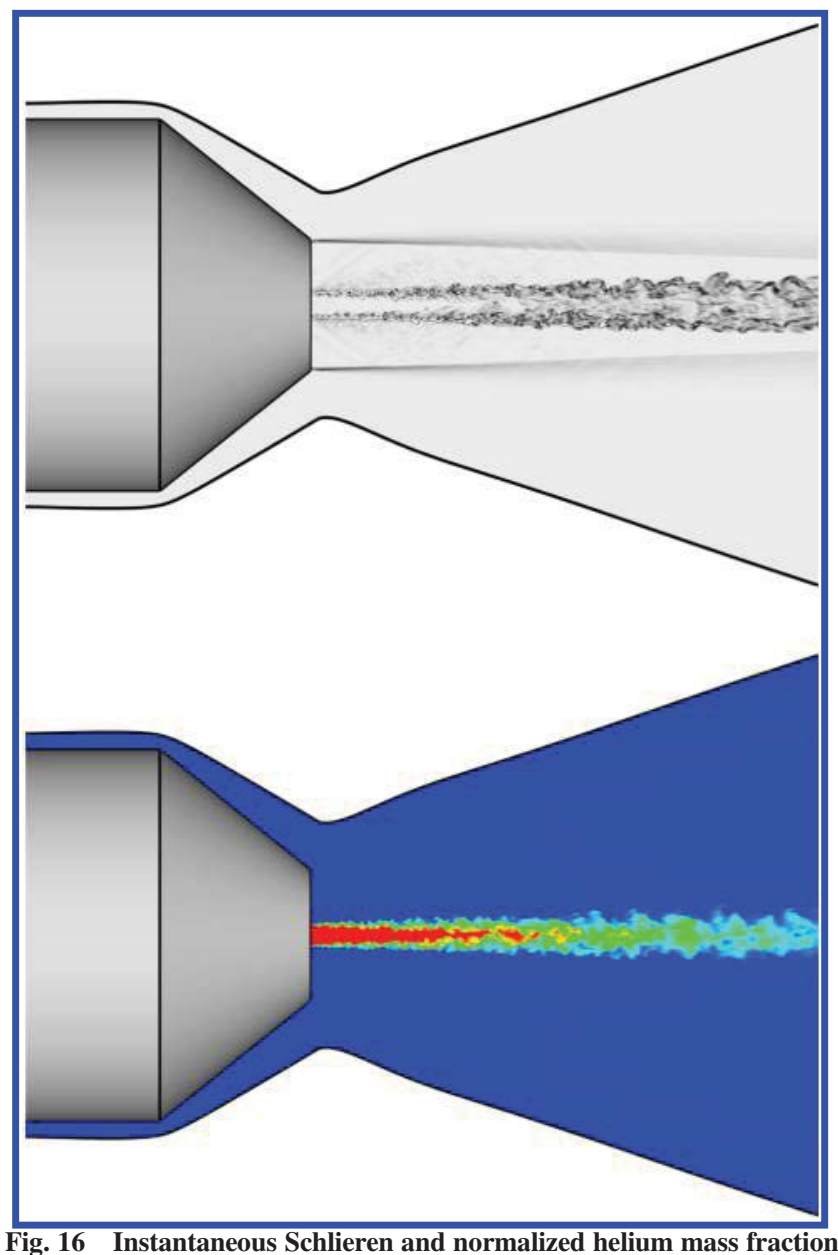
contours. 
added to the helium to allow the streamwise component of velocity to be measured using the RELIEF technique [132]. Details concerning the geometry of the rig and the methodology used for its design and instrumentation can be found in [130]. The flow conditions for the two experiments are given in Tables 1 and 2. The nozzle streams are matched at a Mach number of 1.8. The flow velocity differs significantly, however, with the helium jet velocity more than twice that of the coflow jet and the argon jet velocity around 16\% lower. The convective Mach number is around 0.7 for the helium case and 0.16 for the argon case. Therefore compressibility effects are present for the helium case, and the argon case behaves more like an incompressible flow.
All computational results for the coaxial jet simulation were obtained with the VULCAN code. Details of the numerical method and physical modeling are described in [110]. An azimuthal slice of the 3-D grid generated for the hybrid LES/RANS cases is shown in Fig. 14. Details of the highly resolved region around the jet exit are shown in the insert to the figure. A highly resolved grid containing in excess of 43 million cells is used. The LES portion of the grid in Fig. 14 is shown in detail in Fig. 15.

An instantaneous image of the flowfield for the helium inner jet case is shown in Fig. 16. The upper image shows the magnitude of the density gradient (numerical Schlieren), and the bottom image shows the instantaneous normalized helium mass fraction. Significant

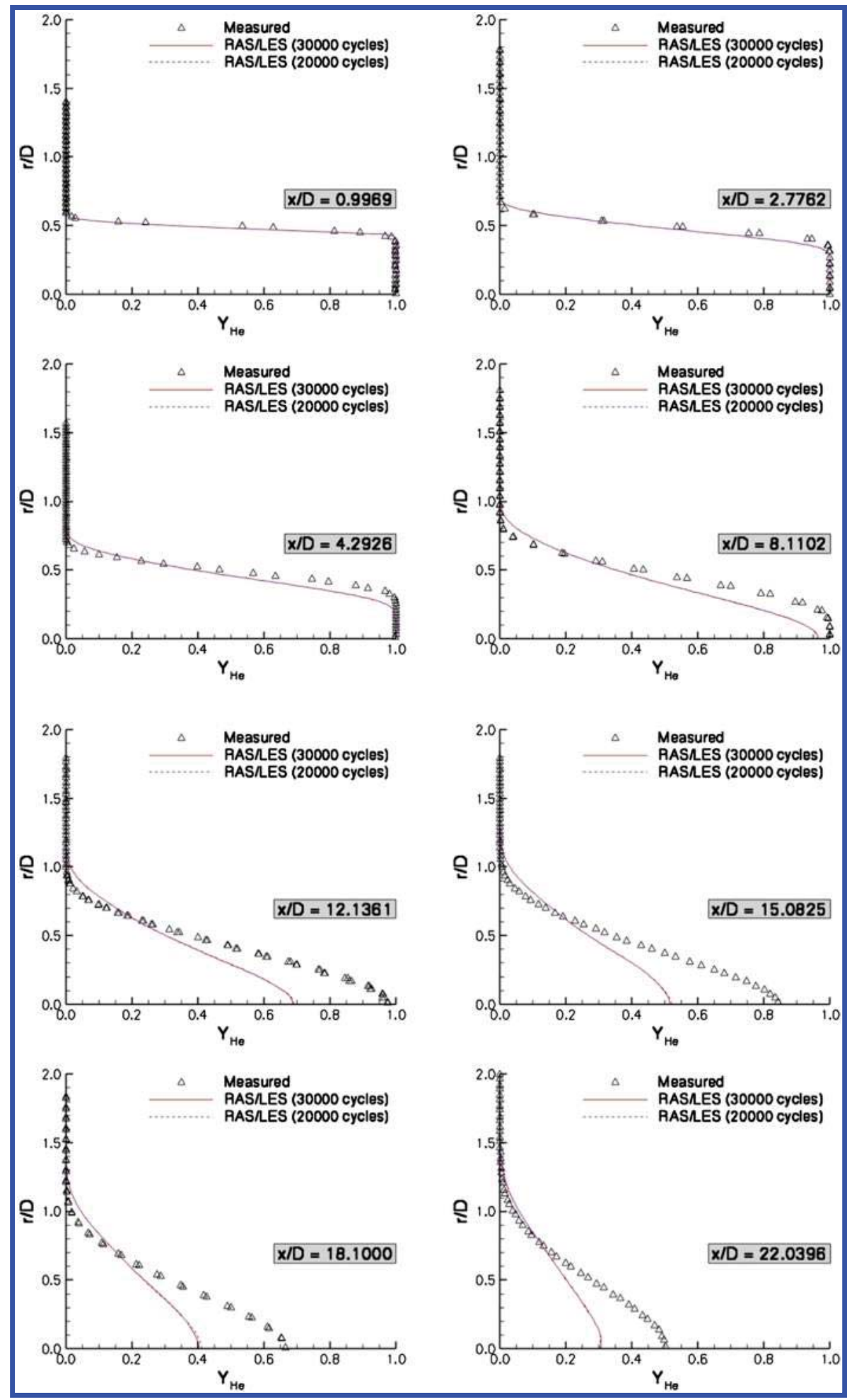

Fig. 17 Comparison of normalized helium mass fraction with measured values. 
turbulent structure has been captured in the simulation. The recirculation zone at the base of the inner nozzle exhibits large-scale unsteadiness that triggers Kelvin-Helmholtz instabilities in the region between the coaxial jets. These instabilities transition downstream to a turbulent state. The turbulent structures provide stirring of the helium and air and result in enhanced mixing. The Schlieren image shows unsteady shock and expansion waves that reflect through the jet structure [110].

Averaged LES/RANS helium mass fraction profiles are compared with experimental measurements in Fig. 17. Overall, the predictions indicate a shear layer growth rate that is more rapid than the data indicate. This may have been caused by too low a level of subgrid scale modeled viscosity resulting from model coefficients chosen to promote the onset of flow instabilities. Suggestions for improvements to this situation are given in [110].

Averaged pitot pressure profiles are compared with the data in Fig. 18. Comparisons of the predictions and data also indicate that the jet mixing has been overpredicted at downstream stations. The predictions and data still agree reasonably well, however.

An instantaneous image of the flowfield for the argon inner jet case is shown in Fig. 19. The upper image again shows the magnitude of the density gradient (numerical Schlieren), and the bottom image shows the instantaneous normalized argon mass fraction. KelvinHelmholtz instabilities are again present in the shear layer between

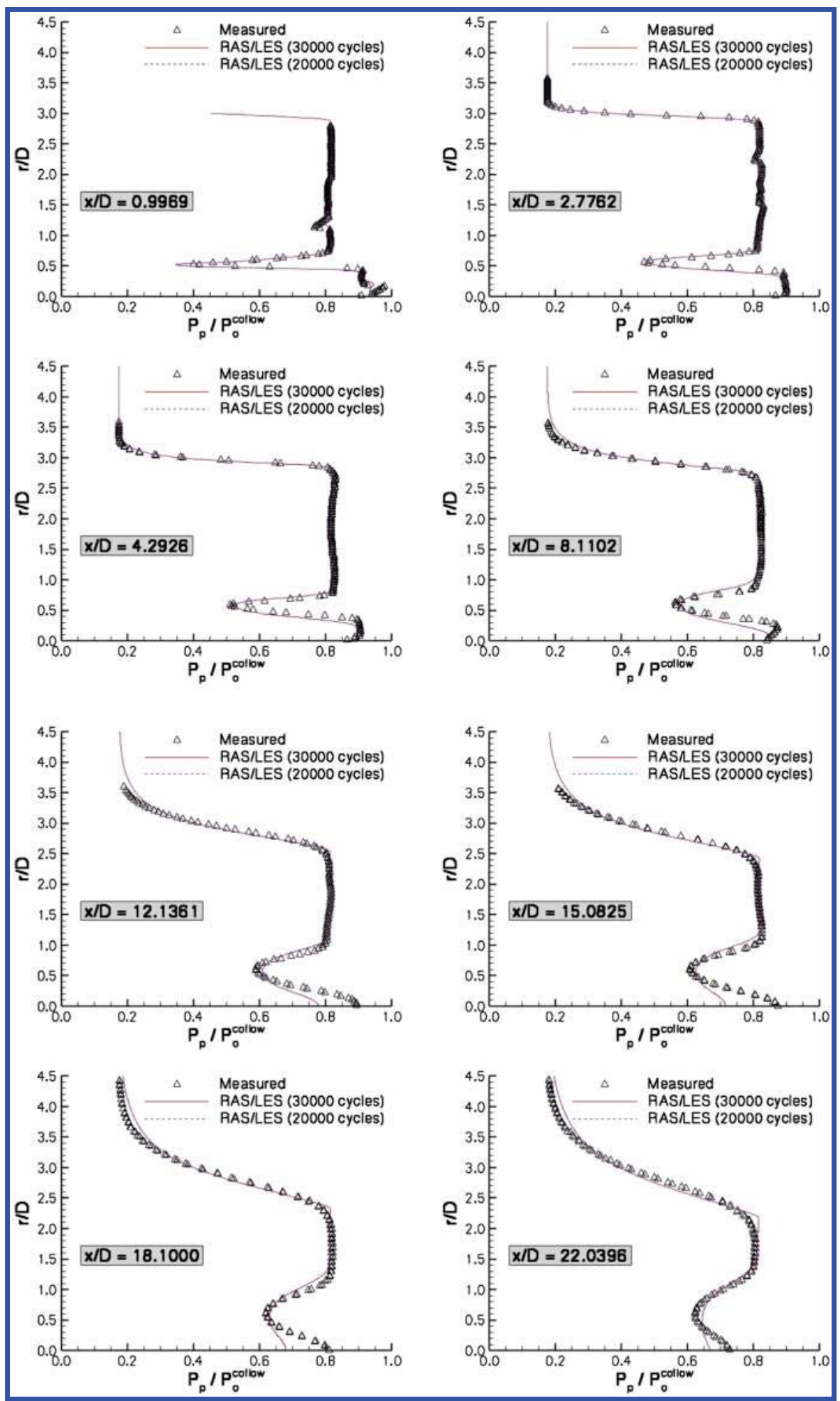

Fig. 18 Comparison of helium pitot pressure with measured values. 


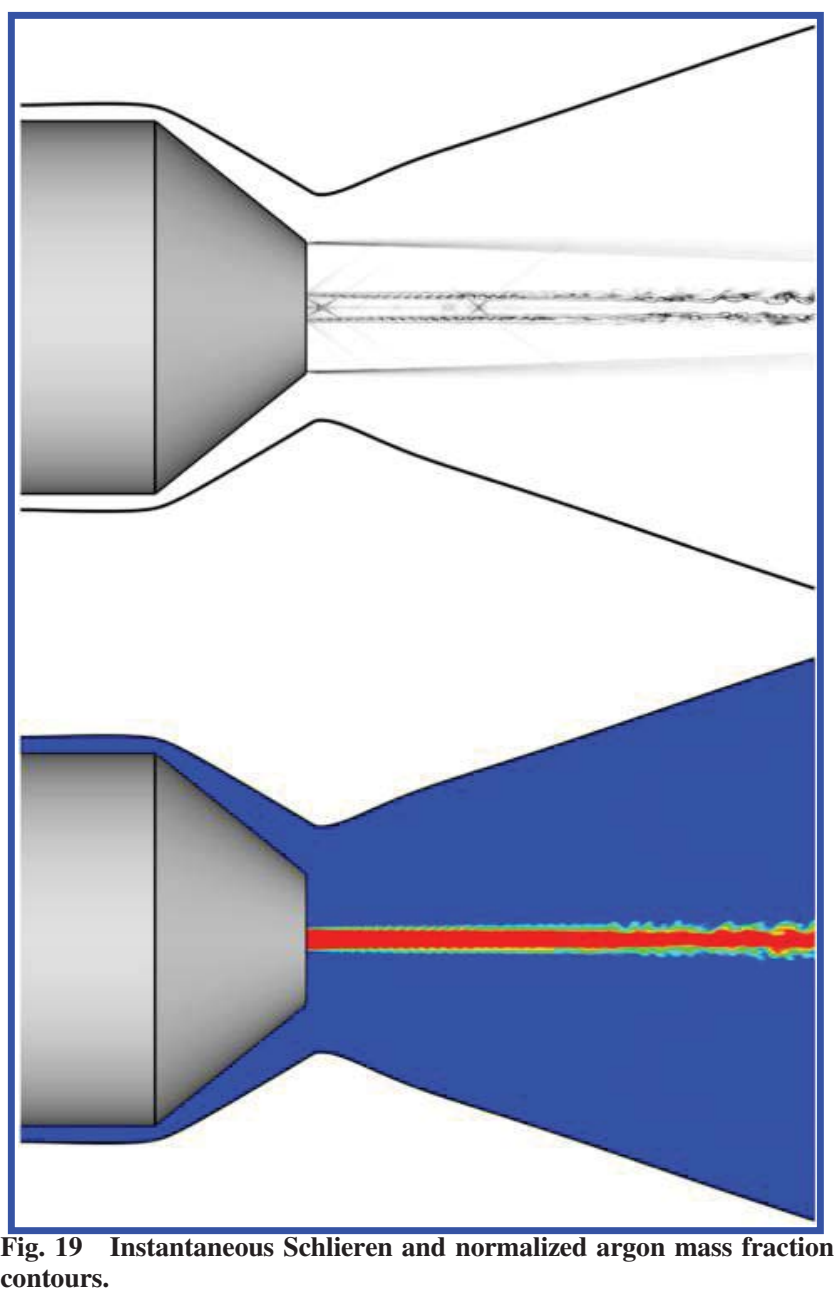

the jets, but they persist longer downstream before beginning to break down. The significantly lower level of shear in the shear layer delays the breakdown. As a result the overall level of stirring and enhanced mixing is reduced in this case.

Averaged LES/RANS argon mass fraction profiles are compared with experimental measurements in Fig. 20. Overall, the predictions indicate a shear layer growth rate that is less rapid than the data indicate. Averaged pitot pressure profiles shown in Fig. 21 also indicate a reduced degree of jet mixing. Again, the predictions and data agree reasonably well.

LES/RANS simulations clearly provide an improvement over RANS simulations [110]. Turbulent structure, which is averaged out in RANS simulations, can be resolved by LES/RANS. Resolution of this structure results in a better definition of turbulent mixing processes although this definition may not be as accurate as desired. There are several ways suggested by [110] that offer the possibility for improvement in the method, and work is continuing to incorporate these ideas.

Another activity to develop a code that can be applied to highspeed combustor flows began in 1993. The WIND code is a structured or unstructured compressible Navier-Stokes solver for modeling reacting internal or external turbulent flows [133-137]. Spatial differencing employs either the Roe scheme [57], the Harten, Lax, van Leer Contact (HLLC) solver [138], the Harten, Lax, van Leer and Einfeldt (HLLE) solver [139] or the Rusanov scheme [140]. These schemes are available with algorithms ranging from first-order to fifth-order upwind biased schemes for structured grids and first or second order for unstructured grids. For temporal discretization using structured grids, the code can be run in explicit mode using a set of Runge-Kutta methods or implicitly using approximate factorization, Jacobi, Gauss-Seidel, and MacCormack's first-order approximate factorization method [141]. For unstructured grids, point-implicit and line implicit methods are used. For unsteady time-accurate simulations with both structured and unstructured grids, global Newton time stepping or dual time stepping is used with the implicit second-order schemes. Turbulence is modeled in the WIND code with the well-established one- and two-equation turbulent kinetic energy models as well as the Rumsey-Gatski algebraic Reynolds stress model. Chemical reactions are modeled for both structured and unstructured grids using a general finite-rate scheme that can be applied to any defined kinetics mechanism. A summary [137] of the development of the WIND code and its current capabilities is given by Nelson along with a number of additional references and applications.

\section{B. PDF Methods}

PDF methods have been used successfully to simulate turbulent reacting flows since the developments of Pope [142] in the mid1980s. Many of the applications of the method were related to fundamental studies, but they were later successfully extended to turbomachinery and other practical flows. In the mid-1990s, Pope and his students [143-146] extended the method to compressible flows by adding the pressure and the internal energy to the conventional velocity PDF formulation that had been applied to incompressible flows. In this approach, the joint PDF of velocity, turbulent frequency, pressure, specific internal energy (or enthalpy), and mixture fraction was solved using a Lagrangian Monte Carlo method. By adding thermodynamic variables as mentioned in the preceding sections to the PDF equation, full closure of the joint PDF transport equation was obtained [146]. Details are given in that reference.

Other groups also began the development of compressible hybrid PDF methods for high-speed reacting flows. In one effort, Hsu et al. solved the joint PDF of species mass fraction and enthalpy using a Monte Carlo scheme to solve the PDF evolution equation [147]. The procedure was coupled with a compressible CFD flow solver that provided the velocity and pressure fields. The approach was later extended to three dimensions and used to model the flow in a coaxial supersonic burner [148]. Finally, the hybrid PDF method was compared with a traditional moment closure method (using laminar chemistry) for an air piloted turbulent diffusion flame near extinction [149]. Comparisons of the hybrid PDF method with the data showed the technique predicted a turbulent flame structure with peak mean radial temperatures agreeing with the data. The moment closure method predicted a laminarlike flame structure with peak mean radial temperatures in the wrong location and overpredicted by $500 \mathrm{~K}$. Further details are given in the references.

As an alternative to solving an evolution equation for the PDF, other researchers have chosen to assume the mathematical form of the PDF. In one approach discussed earlier with the VULCAN code, interactions between the turbulence field and chemistry were modeled with an assumed beta PDF to account for the effects of temperature fluctuations on chemical reaction rates and a multivariate assumed beta PDF to account for the effect of species fluctuations on species production $[94,95]$. Issues associated with cross correlations of temperature and species, not considered in the previous works, were accounted for using a new assumed PDF approach [150]. The approach was shown to have significant potential as an engineering tool, but further work was also suggested to refine the approach. Other successful modeling approaches considered resolving all scales of the flow but only for a small sample of the flow. An example of these approaches include the linear eddy model [151] and one dimensional turbulence model [152] of Kerstein.

\section{LES/Filtered Density Function Methods for High-Speed Reacting Flows}

In our discussion of LES/RANS and PDF methods, we considered the limitations imposed by conventional RANS modeling. PDF methods provide closures for both RANS and LES albeit for flow scales with different dynamical ranges. LES requires modeling of a smaller dynamical range of scales than RANS because a large portion of the flow is solved exactly. Therefore, LES is a very attractive option for modeling the complex flow phenomena present in the 


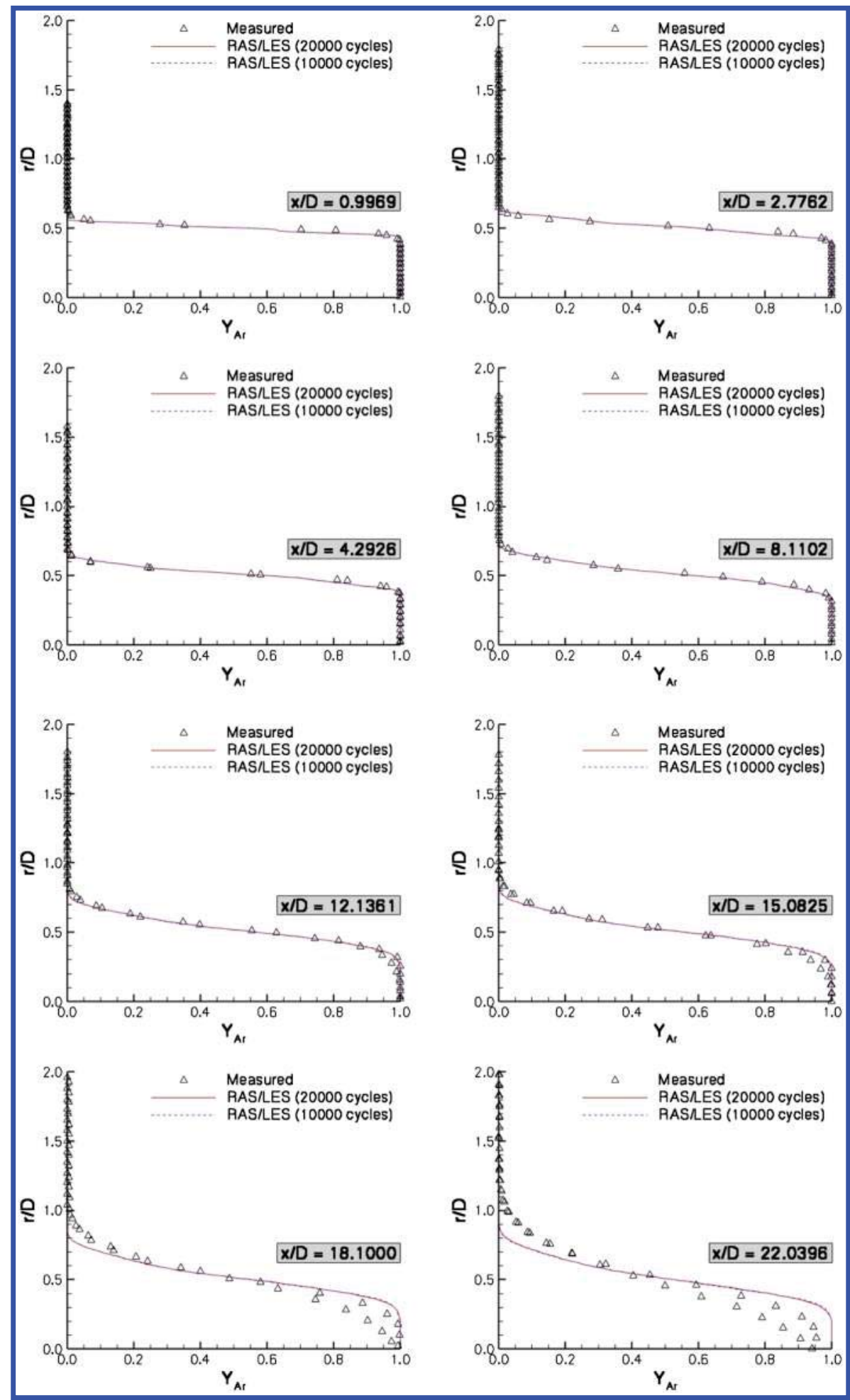

Fig. 20 Comparison of normalized argon mass fraction with measured values.

propulsion system of a hypersonic vehicle. Nik et al. [153] summarize these issues well. They note that

"the physics of high-speed combustion is rich with many complexities. From the modeling standpoint, some of the primary issues are the development of accurate descriptors for turbulence, chemistry, compressibility, and turbulencechemistry interactions. The phenomenon of mixing at both micro- and macro-scales and its role and capability (or lack thereof) to provide a suitable environment for combustion and the subsequent effects of combustion on hydrodynamics are at the heart of hypersonic (and supersonic) physics. From the computational viewpoint, novel strategies are needed to allow affordable simulation of complex flows with stateof-the art physical models. The power of parallel scientific computing now allows inclusion of more complex physical phenomena, which in turn translates into greatly improved predictive capabilities. It is now widely accepted that the optimum means of capturing the detailed, unsteady physics of turbulent combustion is via large-eddy simulation" $[154,155]$. The extension of this approach to actual engine design will certainly require significant additional development and further enhancements in computer resources. But the potential certainly justifies the effort. 
The critical element in successful LES is the accurate modeling of the subgrid scale variables. The filtered density function (FDF) methodology has been effective in providing this closure $[153,156,157]$. The FDF is essentially the PDF of the subgrid scale (SGS) variables. The idea of using the PDF in LES simulations was advanced by Givi [158], but it was the formal definition of FDF by Pope [159] that provided the mathematical foundation of LES/FDF. Following this significant advancement, a number of successes occurred in the development of the LES/FDF method [160-163]. Analogous to the construction of a PDF of specific flow variables, the FDF can consider different flow variables in the context of either incompressible or compressible flow. A sequence of steps were taken beginning with the development of the joint velocity-scalar (temperature, species mass fractions) FDF [164], the filtered mass density function (FMDF), and concluding with the most sophisticated closure to date, the frequency-velocity-scalar FMDF for incompressible flows $[165,166]$. Work is currently underway to develop the FDF method to provide for the LES of high-speed compressible turbulent reacting flows by way of an energy-pressure-velocity-scalar FMDF. A simple form of this FMDF, the scalar FMDF (SFMDF) has been developed and is currently being used to model a high-speed mixing flow. Details of the formulation of the method and its application are given by Nik et al. [153].

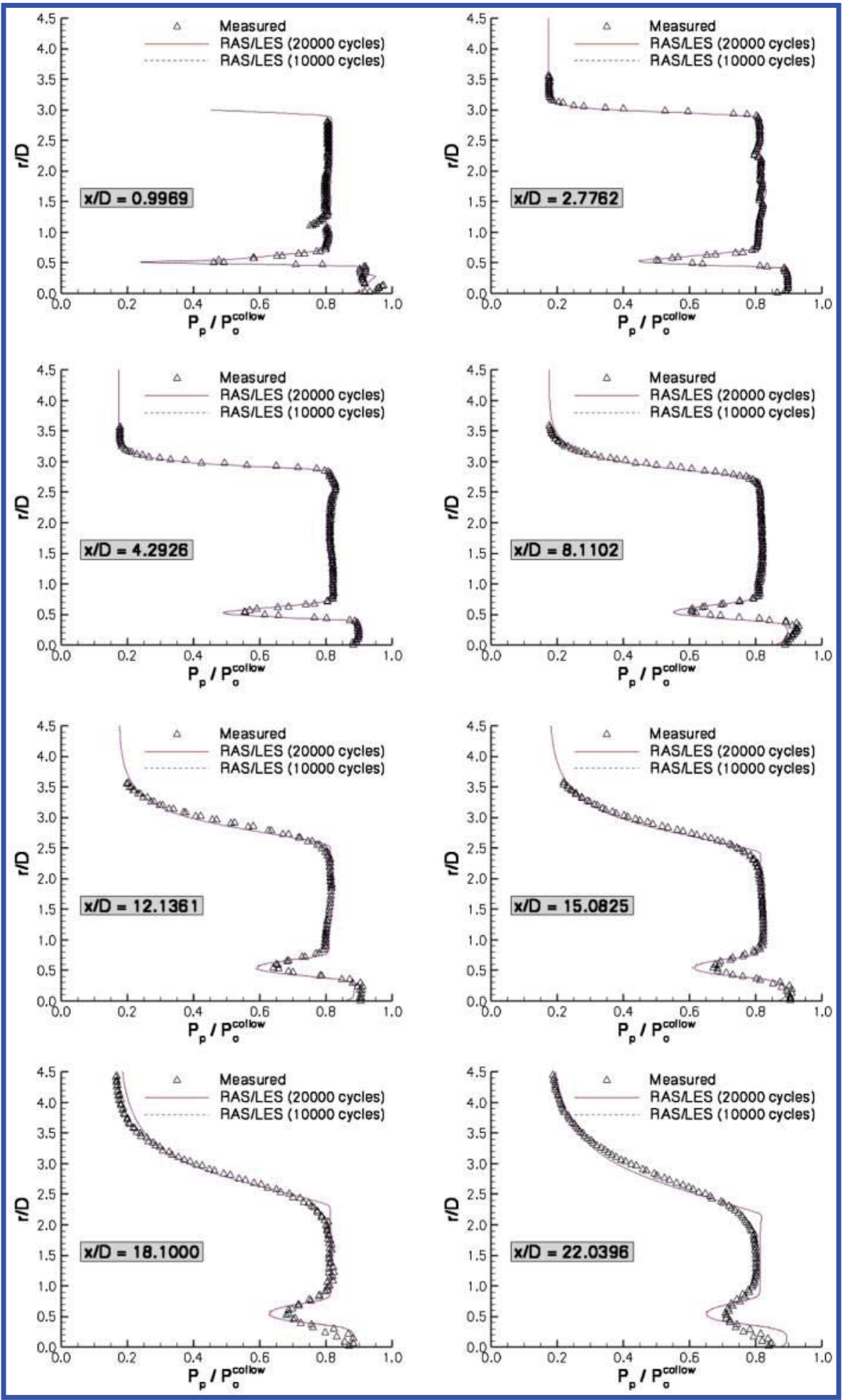

Fig. 21 Comparison of argon pitot pressure with measured values. 


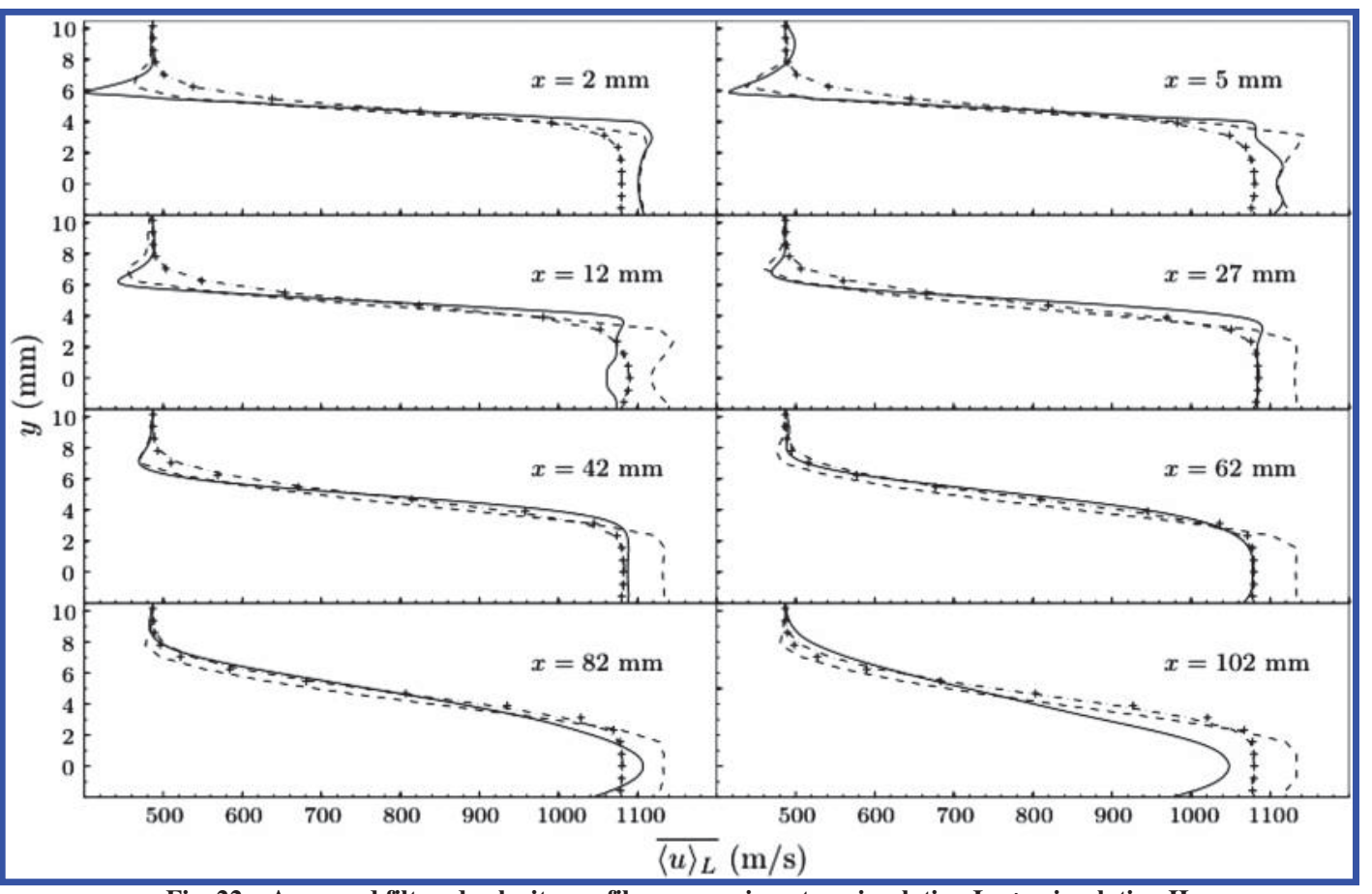

Fig. 22 Averaged filtered velocity profiles: - experiment, - simulation I, -+- simulation II.

Using the SFMDF methodology, the LES of the coaxial nozzle assembly of Cutler et al. [130] was carried out. A schematic of the coaxial nozzle assembly is shown in Fig. 13. Recall that this is the same case that was simulated by the VULCAN LES/RANS code earlier in the paper. Only the helium-air case is considered. The flow conditions are given in Table 1. Computations were performed on a domain spanning 121 by 50 by $50 \mathrm{~mm}$ diameters in the streamwise $x$, cross stream $y$, and spanwise $z$ directions, with a Cartesian grid with 158 by 65 by 65 nodes, respectively. The flowfield was initialized to the inlet-averaged filtered values. Other details of the computation are given in [153].

Results for the simulations are given in Figs. 22 and 23, providing values of the time-averaged, Favre-filtered axial velocity $\overline{\langle u\rangle_{L}}$ and mass fraction $\overline{\left\langle\phi_{\mathrm{He}-\mathrm{O}_{2}}\right\rangle_{L}}$ at a number of cross-stream stations along the center jet's streamwise direction. The angle brackets and overbars denote filtered value and time average, respectively. Simulation I uses fixed coefficients, and simulation II uses a dynamic model as described in [153]. By examining the figures, it is seen that the dynamic model provides better agreement for velocity, whereas the average helium mass fraction is better predicted using fixed coefficients. The authors indicated that they will revisit the coaxial jet case with the more sophisticated closures as their development is completed.

A number of additional cases have been simulated with LES/FDF methods including high-speed mixing [167], flows with shocks [168], and combusting flows [169-172]. One of these interesting cases considered the LES of turbulent nonreacting and reacting flow in an axisymmetric dump combustor [172]. For the reacting cases,

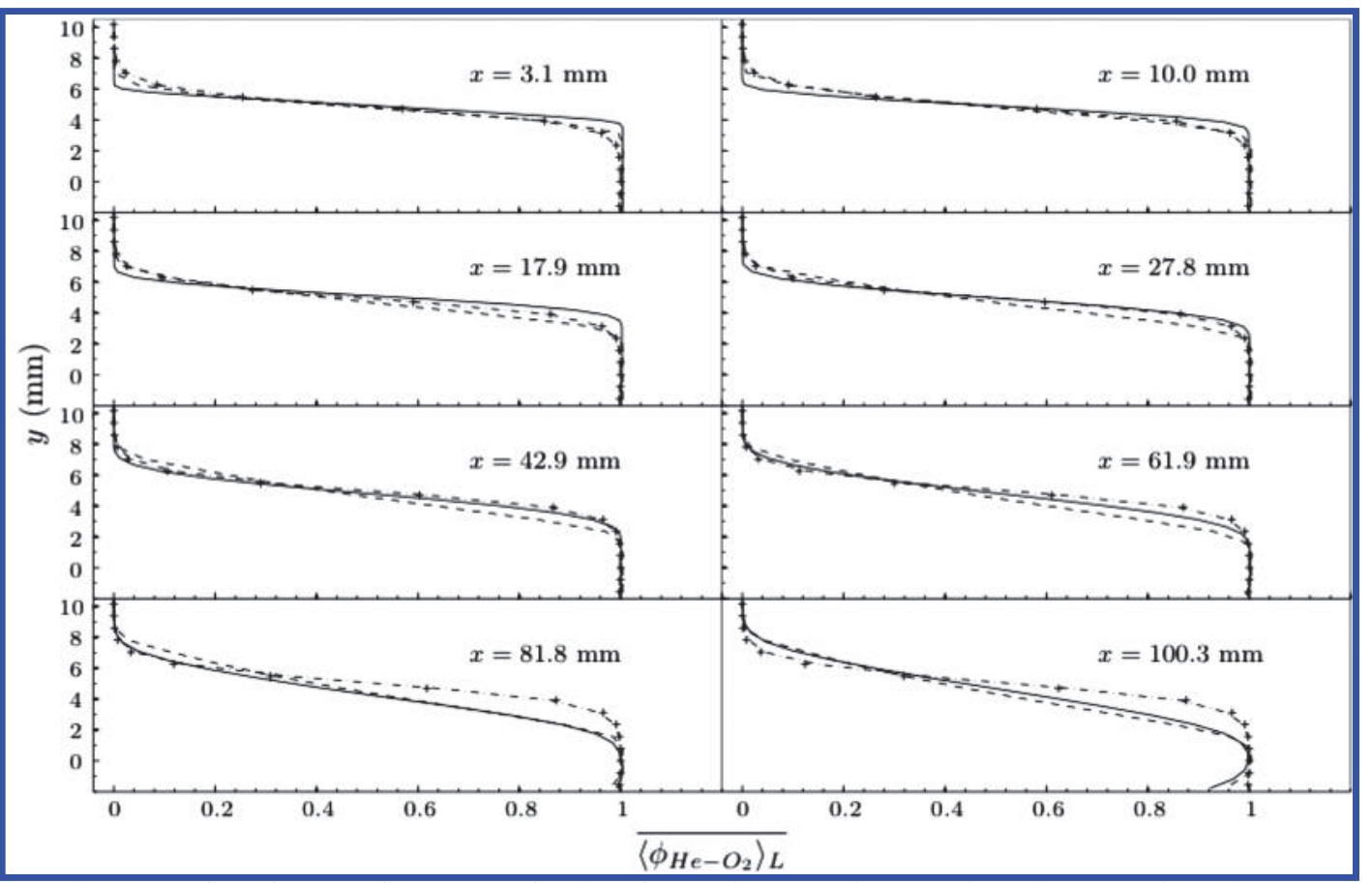

Fig. 23 Profiles of average filtered mass fraction of center jet: - experiment, - simulation I, -+- simulation II. 


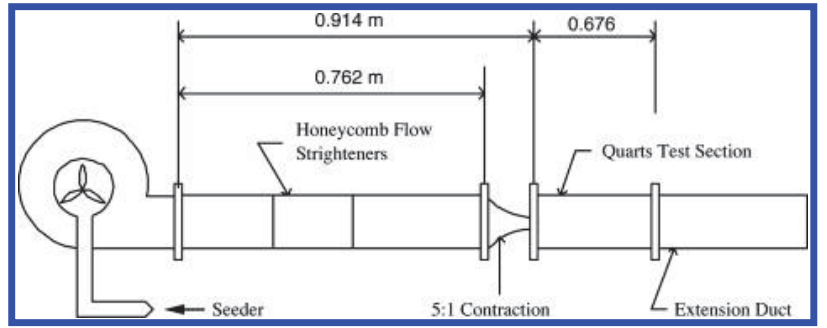

a)
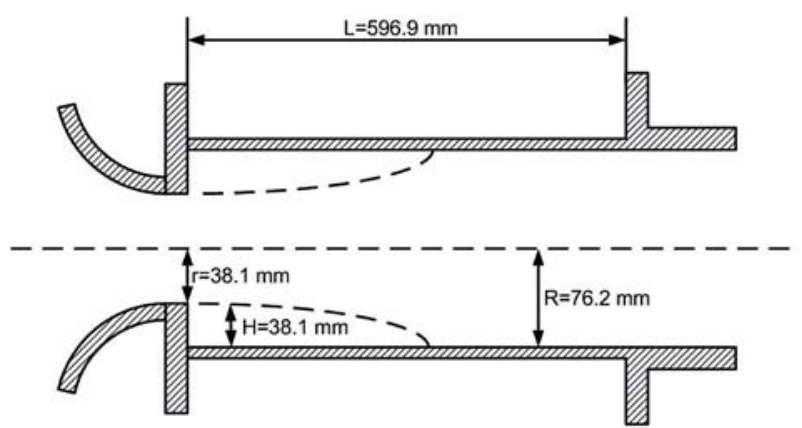

b)

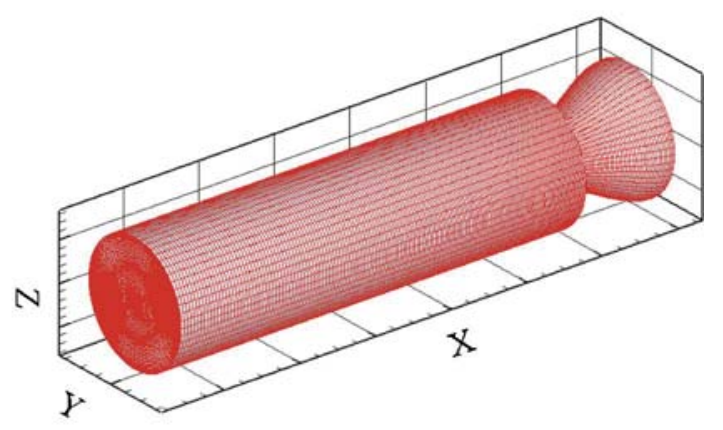

c)

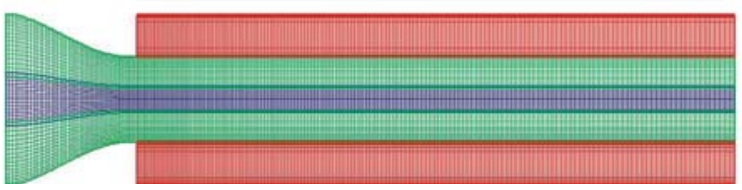

d)

Fig. 24 Schematic of a) experimental setup and b) dump combustor and c) the computational grid and $d$ ) its cross section.

the fuel introduced into the dump combustor was propane at a fuel equivalence ratio of 0.5 . Chemistry was modeled with a one-step global reaction mechanism [173]. The LES/FMDF methodology was used along with a high-order, structured-grid multiblock with a compact finite difference numerical scheme. Details are given in [172]. The code was first validated against relevant data and then used to simulate the dump combustor. The results were then compared with available experimental data from Gould et al. [174,175].

A schematic of the experimental setup, the dump combustor, and the computational grid, with an image of its cross section, is given in Fig. 24. The grid is clustered near the walls, in the shear layer that forms off the step and at the inflow location.

Results for the nonreacting case are given in Figs. 25 through 27. Figure 25 shows the radial variations of the time-averaged Favrefiltered axial velocity, referred to henceforth as the mean velocity, at several axial locations obtained by LES with various SGS stress models. Comparisons of the results with data are also shown. Results are given for the a) Smagorinsky model $\left(C_{d}=0.01\right)$, b) Smagorinsky model $\left.\left(C_{d}=0.028\right), \mathrm{c}\right)$ modified kinetic energy viscosity (MKEV) closure model, d) dynamic Smagorinsky model, and e) Renormalization group (RNG) model. $C_{d}$ in Fig. 25 is the Smagorinsky model coefficient. Mean velocities obtained with the Smagorinsky model

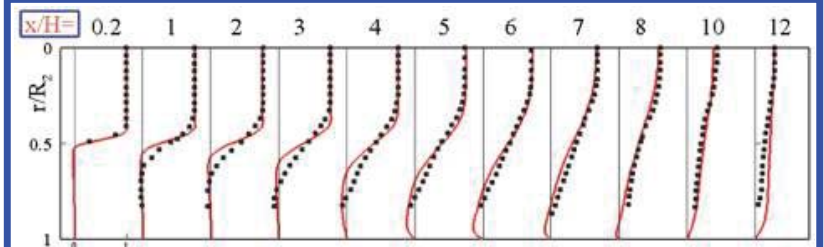

a)

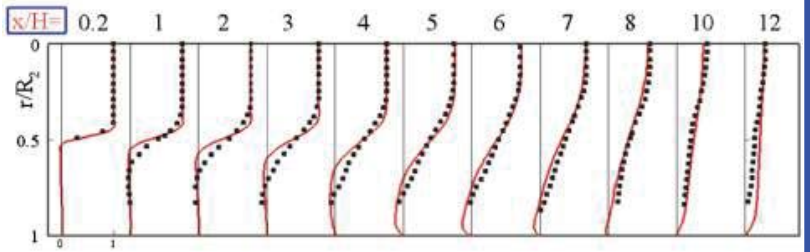

b)

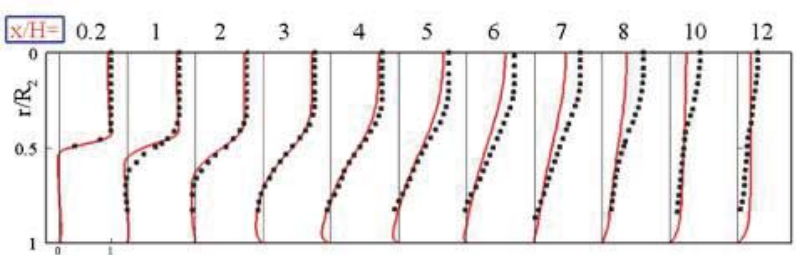

c)

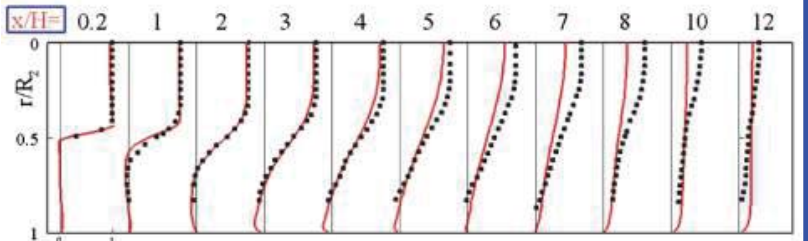

d)

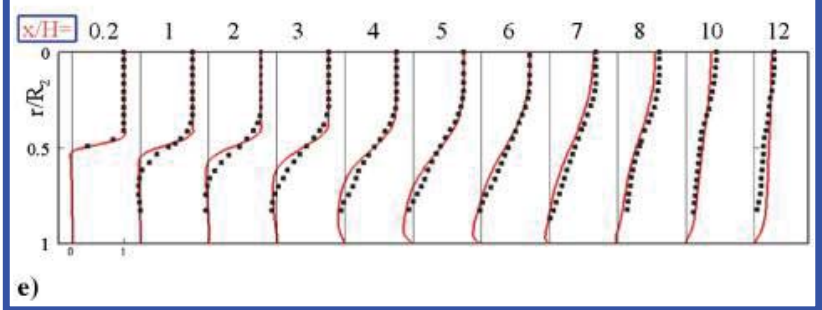

Fig. 25 Comparison between LES and experimental data with different SGS models for mean axial velocity $(\bullet$, experiment; solid lines, LES).

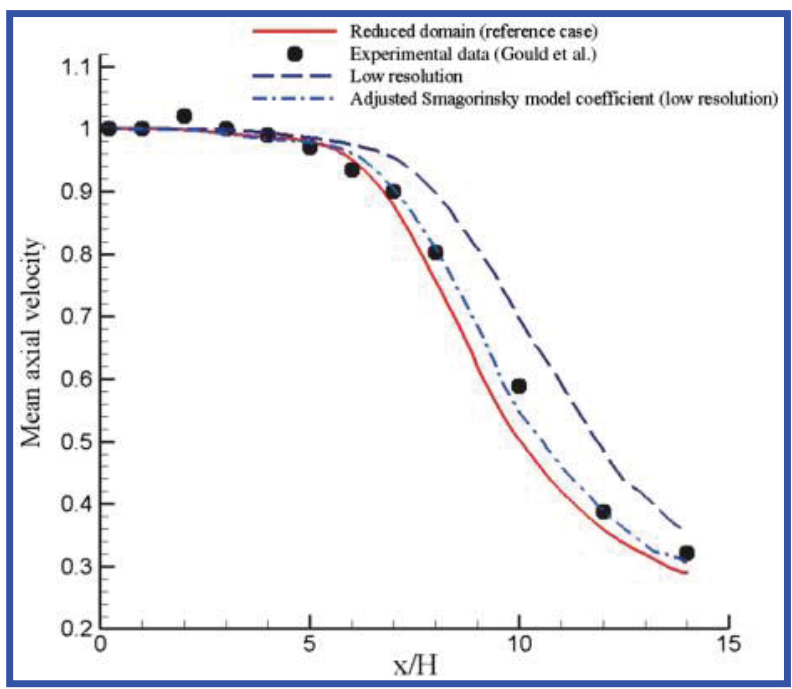

Fig. 26 Axial variations of centerline velocity. 


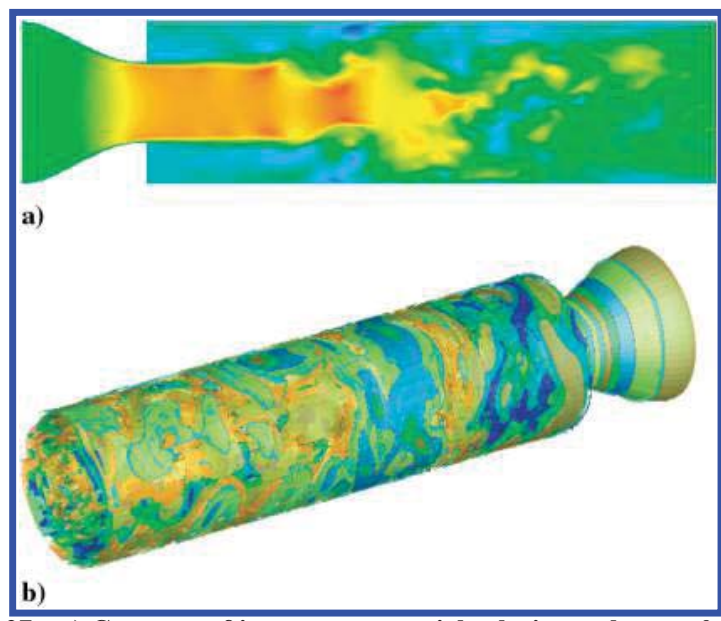

Fig. 27 a) Contours of instantaneous axial velocity at the $z=0$ plane and b) isosurfaces of vorticity magnitude.

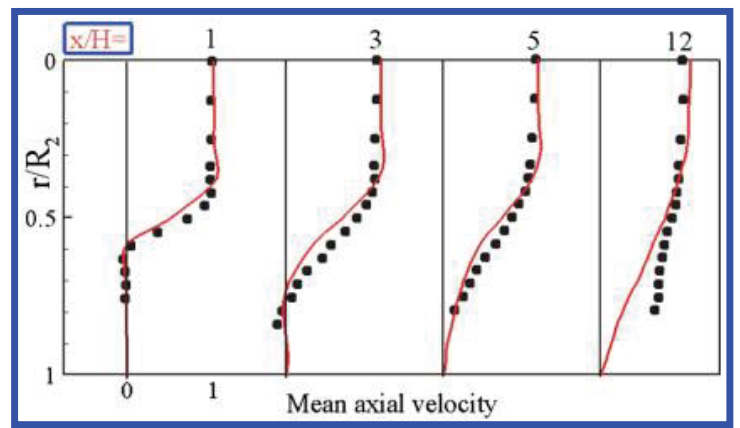

Fig. 28 Radial variations of mean axial filtered velocity compared with data for reacting case $(\bullet$, experiment; solid lines, LES).

with the larger coefficient and the RNG model compare reasonably well with the experimental data. Close to the inflow, the dynamic Smagorinsky model gives slightly better results [172]. Figure 26 shows the centerline mean velocity decay in the dump combustor. This decay was plotted as a function of different grid resolutions and adjusted Smagorinsky model coefficients. Finally, Fig. 27 diagrams the instantaneous axial velocity at the $z=0$ plane and isosurfaces of vorticity magnitude. The turbulent structure that is present in the dump combustor can be readily appreciated in this figure.

Results for the reacting flow cases are given in Figs. 28 through 31 . The configuration differs somewhat from the nonreacting case due to the addition of an upstream nozzle to allow better definition of inflow boundary conditions [172]. Figure 28 compares the computed radial variations of mean axial velocity with experimental data at four downstream stations. Radial variations of mean filtered temperature are compared with data in Fig. 29. The axial velocity compares quite well with the data until the last station where the computation shows more rapid mixing away from the centerline. The predicted temperature agrees fairly well with the data downstream but overpredicts the upstream data in the flameholding region behind the step. Twodimensional contour plots of instantaneous filtered temperature and

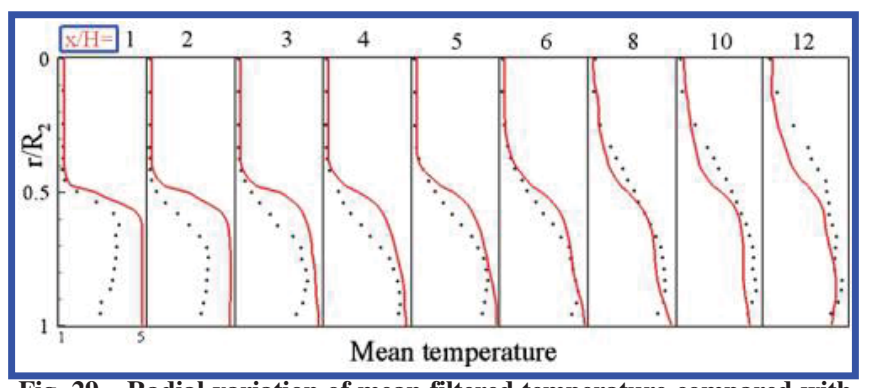

Fig. 29 Radial variation of mean filtered temperature compared with data for reacting case $(\bullet$, experiment; solid lines, LES).

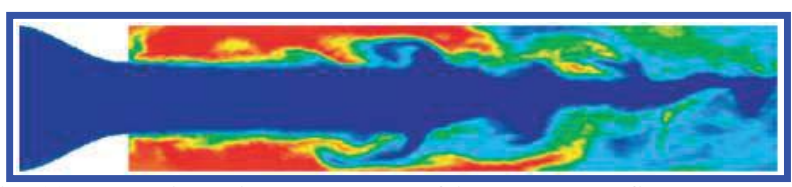

Fig. 30 Two-dimensional contours of instantaneous filtered temperature for reacting case.

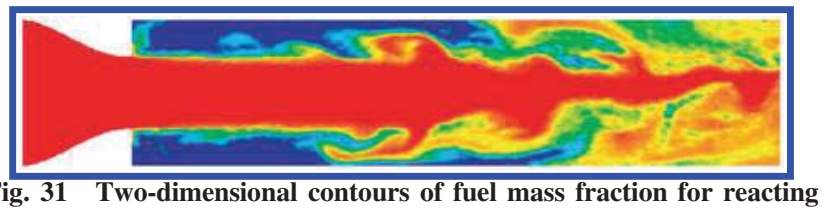
case.

fuel (propane) mass fraction are given in Figs. 30 and 31. The temperature contours in Fig. 30 indicate high temperatures at and downstream of the step as expected in dump combustor configurations. The turbulent nature of the combustion processes is also quite apparent. The fuel mass fraction contours in Fig. 31 show nearly complete consumption of fuel in the recirculation zone behind the step and the turbulent mixing and combustion of fuel beyond that station. The mixing and combustion processes also penetrate significantly into the fuel core when proceeding downstream from the same station. More comparisons of the simulation results with data and further discussions of the comparisons are given in [172].

\section{Conclusions}

This paper discusses the evolution over the past 40 years of computational methods for modeling high-speed reacting flowfields, particularly the flowfields in scramjets and other high-speed propulsion systems. The discussion follows several hypersonic programs and the flight vehicles that resulted from the programs. The NASP program and the technology programs that followed provided strong motivation for advancing the computational capabilities of the country in both the government and private sectors. Although the NASP program was not successful in developing a hypersonic vehicle, it did spawn the development of new computational capabilities. The Hyper-X Program beginning in 1995 revived highspeed computational research and development. This program culminated with the successful flight of two hypersonic vehicles in 2004. A flight program is the catalyst that drives technology development and synthesizes all of the efforts into a unified tool for development of the ultimate experiment, the flight of a hypersonic vehicle. The genesis of most of the current day state-of-the-art computational tools for scramjet research and development began with this program. This paper attempts to cover this story from NASP and Hyper-X to the present day. A number of computer codes evolved during this period of time. The codes fell into three classes, including Reynolds-averaged Navier-Stokes codes, hybrid Reynolds-averaged large-eddy simulation codes, and large-eddy simulation codes. RANS/LES codes are evolving into the workhorse codes for scramjet flowpath development in this decade, and LES/FDF methodology appears to offer the most promise for work in the future.

\section{References}

[1] Billig, F. S., "Research on Supersonic Combustion," Journal of Propulsion and Power, Vol. 9, No. 4, 1993, pp. 499-514. doi:10.2514/3.23652

[2] Curran, E. T., "Scramjet Engines: The First Forty Years," Journal of Propulsion and Power, Vol. 17, No. 6, 2001, pp. 1138-1148. doi: $10.2514 / 2.5875$

[3] Hallion, R. P., "The History of Hypersonics: Or, "Back to the FutureAgain and Again"," AIAA Paper 2005-0329, 2005.

[4] Ferri, A., "Possible Directions of Future Research in Air Breathing Engines," Proceedings of the Fourth AGARD Colloquium, Pergamon, New York, 1961. 
[5] Dugger, D. L., "Comparison of Hypersonic Ramjet Engines with Subsonic and Supersonic Combustion," Proceedings of the Fourth AGARD Colloquium, Pergamon, New York, 1961.

[6] Weber, R. J., and MacKay, J. S., "Analysis of Ramjet Engines Using Supersonic Combustion," NACA TN-4386, 1958.

[7] Northam, G. B., and Anderson, G. Y., "Linear Stability Analysis of Density Stratified Parallel Shear Flows," AIAA Paper 1986-0159, 1986.

[8] White, M. E., Drummond, J. P., and Kumar, A., "Evolution and Application of CFD Techniques for Scramjet Engine Applications,' Journal of Propulsion and Power, Vol. 3, No. 5, 1987, pp. 423-439. doi: $10.2514 / 3.23007$

[9] Waltrup, P. J., and Billig, F. S., "Liquid Fueled Supersonic Combustion Ramjets; A Research Perspective of the Past, Present, and Future," AIAA Paper 1986-0158, 1986

[10] Billig, F. S., Waltrup, P. J., and Stockbridge, R. D., "Integral-Rocket Dual-Combustion Ramjets; A New Propulsion Concept," Journal of Spacecraft and Rockets, Vol. 17, No. 5, 1980, pp. 416-424. doi: $10.2514 / 3.57760$

[11] Ferri, A., "Mixing Controlled Supersonic Combustion," Annual Review of Fluid Mechanics, Vol. 5, 1973, pp. 301-338. doi:10.1146/annurev.fl.05.010173.001505

[12] Moretti, G., "Analysis of Two-Dimensional Problems of Supersonic Combustion Controlled by Mixing," AIAA Paper 1964-96, 1964.

[13] Edelman, R., and Weilerstein, G., "A Solution of the InviscidViscid Equations with Applications to Bounded and Unbounded Multicomponent Reacting Flows," AIAA Paper 1969-0083, 1969.

[14] Dash, S. M., "An Analysis of Internal Supersonic Flows with Diffusion, Dissipation, and Hydrogen-Air Combustion," NASA CR111783,1970

[15] Dash, S. M., and DelGuidice, P. D., "Analysis of Supersonic Combustion Flowfields with Embedded Subsonic Regions," NASA CR-112223, 1972.

[16] Elghobashi, S. E., and Spalding, D. B., "Equilibrium Chemica Reaction of Supersonic Hydrogen-Air Jets," NASA CR-2725, 1977.

[17] Spalding, D. B., Launder, B. E., Morse, A. P., and Maples, G., "Combustion of Hydrogen-Air Jets in Local Chemical Equilibrium," NASA CR-2407, 1974

[18] Markatos, N. C., Spalding, D. B., and Tatchell, D. G., "Combustion of Hydrogen Injected into a Supersonic Airstream," NASA CR-2802, 1977.

[19] Patankar, S. V., and Spalding, D. B., "Calculation Procedure for Heat, Mass, and Momentum Transfer in Three-Dimensional Parabolic Flows," International Journal of Heat and Mass Transfer, Vol. 15, No. 10,1972 , pp. 1787-1806. doi:10.1016/0017-9310(72)90054-3

[20] Evans, J. S., and Schexnayder, C. J., "Critical Influence of Finite Rate Chemistry and Unmixedness on Ignition and Combustion of Supersonic H2-Air Streams," AIAA Paper 1979-0355, 1979.

[21] Dash, S. M., Sinha, N., and York, B. J., "Implicit/Explicit Analysis of Interactive Phenomena in Supersonic Chemically Reacting Mixing and Boundary Layer Problems," AIAA Paper 1985-1717, 1985.

[22] MacCormack, R. W., "The Effect of Viscosity in Hypervelocity Impact Catering," AIAA Paper 1969-0354, 1969.

[23] Briley, W. R., and McDonald, H., "Solution to the Multi-Dimensional Compressible Navier-Stokes Equations by a Generalized Implicit Method," Journal of Computational Physics, Vol. 24, No. 4, 1977, pp. 372-397. doi:10.1016/0021-9991(77)90029-8

[24] Beam, R., and Warming, R. F., "An Implicit Factored Scheme for the Compressible Navier-Stokes Equations," AIAA Journal, Vol. 16, No. 4,1978 , pp. 393-402. doi:10.2514/3.60901

[25] Drummond, J. P., "Numerical Solution for Perpendicular Sonic Hydrogen Injection into a Ducted Supersonic Airstream," AIAA Journal, Vol. 17, No. 5, 1979, pp. 531-533. doi: $10.2514 / 3.61168$

[26] Drummond, J. P., "Numerical Investigation of the Perpendicular Injector Flow Field in a Hydrogen Fueled Scramjet," AIAA Paper $1979-1482,1979$

[27] Drummond, J. P., and Weidner, E. H., "Numerical Study of a Scramjet Engine Flow Field," AIAA Journal, Vol. 20, No. 9, 1982, pp. 1182 1187 doi: $10.2514 / 3.51178$

[28] Drummond, J. P., and Weidner, E. H., "A Numerical Study of Candidate Transverse Fuel Injector Configurations in the Langley Scramjet Engine," Proceedings of the 17th JANNAF Combustion Meeting, Chemical Propulsion Information Agency, Laurel, MD, 1980.

[29] Weidner, E. H., and Drummond, J. P., "Numerical Study of Staged Fuel Injection for Supersonic Combustion," AIAA Journal, Vol. 20, No. 10,
1982 , pp. $1426-1431$. doi: $10.2514 / 3.51202$

[30] Schetz, J. A., Billig, F. S., and Favin, S., "Flowfield Analysis of a Scramjet Combustor with a Coaxial Fuel Jet," AIAA Journal, Vol. 20, No. 9, 1982, pp. 1268-1274. doi:10.2514/3.51187

[31] Schetz, J. A., "Turbulent Mixing of a Jet in a Co-Flowing Stream," AIAA Journal, Vol. 6, No. 10, 1968, pp. 2008-2010. doi:10.2514/3.4916

[32] Schetz, J. A., Billig, F. S., and Favin, S., "Analysis of Mixing and Combustion in a Scramjet Combustor with a Coaxial Fuel Jet," AIAA Paper 1980-1256, 1980.

[33] Griffin, M. D., Billig, F. S., and White, M. E., "Applications of Computational Techniques in the Design of Ramjet Engines," 6th International Symposium on Air Breathing Engines, AIAA, New York, 1983, pp. 215-228.

[34] Walthrup, P. P., Anderson, G. Y., and Stull, F. D., "Supersonic Combustion Ramjet (Scramjet) Engine Development in the United States," 3rd International Symposium on Air Breathing Engines, Munich, Germany, 1976, pp. 835-861.

[35] Jenkins, D. R., Landis, T., and Miller, J., "American X-Vehicles-An Inventory-X-1 to X-50," NASP SP-4531, 2003.

[36] Drummond, J. P., Rogers, R. C., and Hussaini, M. Y., "A Detailed Numerical Model of a Supersonic Reacting Mixing Layer," AIAA Paper 1986-1427, 1986.

[37] Carpenter, M. H., and Kamath, H., "Three-Dimensional Extensions to the SPARK Combustion Code," NASP CP-5029, 1988.

[38] Carpenter, M. H., "A Generalized Chemistry Version of SPARK," NASA CR-4196, 1988.

[39] Chitsomboon, T., and Northam, G. B., "A 3-D PNS Computer Code for the Calculation of Supersonic Combusting Flows," AIAA Paper 19880438, 1988.

[40] Chitsomboon, T., "Numerical Study of Hydrogen-Air Supersonic Combustion by Using Elliptic and Parabolized Equations," Ph.D. Thesis, Department of Mechanical Engineering, Old Dominion Univ., Norfolk, VA, 1986.

[41] Chitsomboon, T., Kumar, A., and Tiwari, S. N., "Numerical Study of Finite-Rate Supersonic Combustion Using Parabolized Equations," AIAA Paper 1987-0088, 1987.

[42] Korte, J. J., and McRae, D. S., "Explicit Upwind Algorithm for the Parabolized Navier-Stokes Equations," AIAA Paper 1988-0716, 1988

[43] White, J. A., Korte, J. J., and Gaffney, R. L., "Flux-Difference Split Parabolized Navier-Stokes Algorithm for Nonequilibrium Chemically Reacting Flows," AIAA Paper 1993-0534, 1993.

[44] Guilda, T., and McRae, D., "An Accurate, Stable, Explicit, Parabolized Navier-Stokes Solver for High Speed Flows," AIAA Paper 19861116,1986

[45] Gielda, T. P., Hunter, L. G., and Chawner, J. R., "Efficient Parabolized Navier-Stokes Solutions of Three-Dimensional, Chemically Reacting Scramjet Flow Fields," AIAA Paper 1988-0096, 1988.

[46] Boris, J. P., A Fluid Transport Algorithm that Works. Computing as a Language of Physics, International Atomic Energy Agency, Vienna, Austria, 1971, pp. 171-189.

[47] Boris, J. P., "Flux-Corrected Transport I: SHASTA—A Fluid Transport Algorithm that Works," Journal of Computational Physics, Vol. 11, No. 1,1973 , pp. 38-69. doi:10.1016/0021-9991(73)90147-2

[48] Oran, E. S., Numerical Simulation of Reactive Flow, Elsevier, New York, 1987, pp. 264-298.

[49] Zalesak, S. T., "Fully Multidimensional Flux-Corrected Transport Algorithms for Fluids," Journal of Computational Physics, Vol. 31, No. 3, 1979, pp. 335-362. doi:10.1016/0021-9991(79)90051-2

[50] Oran, E. S., and Boris, J. P., Numerical Simulation of Reactive Flow, Cambridge Univ. Press, New York, 2001, pp. 246-267.

[51] MacCormack, R. W., "Current Status of Numerical Solutions of the Navier-Stokes Equations," AIAA Paper 1985-0032, 1985.

[52] Steger, J. L., "Flux Vector Splitting of the Inviscid Gasdynamic Equations with Applications to Finite-Difference Methods," Journal of Computational Physics, Vol. 40, No. 2, 1981, pp. 263-293. doi:10.1016/0021-9991(81)90210-2

[53] Candler, G. V., and MacCormack, R. W., "Hypersonic Flow Past 3-D Configurations," AIAA Paper 1987-0480, 1987.

[54] Candler, G. V., and MacCormack, R. W., "The Computation of Hypersonic Ionized Flows in Chemical and Thermal Nonequilibrium," AIAA Paper 1988-0511, 1988.

[55] Grossman, B., and Walters, R. W., "The Computation of Hypersonic Ionized Flows in Chemical and Thermal Nonequilibrium," AIAA Paper 1987-1117, 1987. 
[56] van Leer, B., "Flux-Vector Splitting for the Euler Equations," Lecture Notes in Physics, Vol. 170, 1982, pp. 507-512. doi:10.1007/3-540-11948-5_66

[57] Roe, P. L., "Characteristic-Based Schemes for the Euler Equations," Annual Review of Fluid Mechanics, Vol. 18, 1986, pp. 337-365.

[58] Anderson, W. K., Thomas, J. L., and van Leer, B., "A Comparison of Finite-Volume Flux Vector Splittings for the Euler Equations," AIAA Paper 1985-0122, 1985.

[59] Walters, R. W., and Dwoyer, D. L., "An Efficient Iteration Strategy Based on Upwind/Relaxation Schemes for the Euler Equations," AIAA Paper 1985-1529-CP, 1985.

[60] Grossman, B., and Cinnella, P., "The Development of Flux-Split Algorithms for Flows with Nonequilibrium Thermodynamics and Chemical Reactions," AIAA Paper 1988-3596, 1988.

[61] Grossman, B., and Cinnella, P., "Flux-Split Algorithms for Flows with Nonequilibrium Chemistry and Vibrational Relaxation," Journal of Computational Physics, Vol. 88, 1990, pp. 131-168.

[62] Liou, M. S., van Leer, B., and Shuen, J. S., "Splitting of Inviscid Fluxes for Real Gases," Journal of Computational Physics, Vol. 87, 1990, pp. 1-24. doi:10.1016/0021-9991(90)90222-M

[63] Liou, M. S., "A Generalized Procedure for Constructing an UpwindBased TVD Scheme," AIAA Paper 1987-0355, 1987.

[64] Yee, H. C., "Construction of Explicit and Implicit Symmetric TVD Schemes and Their Applications," Journal of Computational Physics, Vol. 68, No. 1, 1987, pp. 151-179. doi:10.1016/0021-9991(87)90049-0

[65] Yee, H. C., and Shinn, J. L., "Semi-Implicit and Fully Implicit Shock Capturing Methods for Hyperbolic Conservation Laws with Stiff Source Terms," AIAA Paper 1987-1116-CP, 1987.

[66] Yee, H. C., "Upwind and Symmetric Shock-Capturing Schemes," NASA TM-89464, 1987.

[67] Gnoffo, P. A., McCandless, R. S., and Yee, H. C., "Enhancements to Program LAURA for Computation of Three-Dimensional Hypersonic Flow," AIAA Paper 1987-0280, 1987.

[68] Gnoffo, P. A., and Green, F. A., "A Computational Study of the Flow Field Surrounding the Aeroassist Flight Experiment Vehicle," AIAA Paper 1987-1575, 1987.

[69] Gnoffo, P. A., Gupta, R. N., and Shinn, J. L., "Conservation Equations and Physical Models for Hypersonic Air Flows in Thermal and Chemical Nonequilibrium," NASA TP-2867, 1988.

[70] Shuen, J. S., and Yoon, S., "Numerical Study of Chemically Reacting Flows Using an LU Scheme," AIAA Paper 1988-0436, 1988.

[71] Lee, J., "An Analysis of Supersonic Flows with Low-Reynolds Number Compressible Two-Equation Turbulence Models Using LU Finite Volume Implicit Numerical Techniques," AIAA Paper 1994-0193, 1994

[72] Lee, J., "An Application of Two-Equation Models of Turbulence to Three-Dimensional Chemically Reacting Flows," AIAA Paper 19950734, 1995.

[73] Shuen, J. S., and Yoon, S., "Three-Dimensional Simulation of an Underexpanding Jet Interacting with a Supersonic Cross Flow," AIAA Paper 1988-3181, 1988.

[74] Abarbanel, S., and Kumar, A., "Compact High Order Schemes for the Euler Equations," NASA CR-181625, 1988.

[75] Hussaini, M. Y., Salas, M. D., and Zang, T. A., "Spectral Methods for Inviscid, Compressible Flows," Advances in Computational Transonics, edited by Habashi, W. G., Pineridge, Swansea, U.K., 1985, pp. 875-912.

[76] Gottlieb, D., and Orszag, S. A., "Numerical Analysis of Spectral Methods, Theory, and Applications," CBMS-NSF Regional Conference Series in Applied Mathematics, Capital City Press, Montpelier, Vermont, 1977.

[77] Drummond, J. P., Hussaini, M. Y., and Zang, T. A., "Spectral Methods for Modeling Supersonic Chemically Reacting Flowfields," AIAA Journal, Vol. 24, No. 9, 1986, pp. 1461-1467. doi: $10.2514 / 3.9466$

[78] Drummond, J. P., "Two-Dimensional Numerical Simulation of a Supersonic, Chemically Reacting Mixing Layer," NASA TM-4055, 1988.

[79] McClinton, C. R., and Hicks, J. W., "NASA Scramjet Flights to Breathe New Life into Hypersonics," Aerospace America, Vol. 35, No. 7, 1997, pp. 40-46.

[80] Rausch, V. L., McClinton, C. R., and Crawford, J. L., "Hyper-X: Flight Validation of Hypersonic Airbreathing Technology," 13th International Symposium on Air Breathing Engines, International Society for Air Breathing Engines (ISABE), Chattanooga, TN, ISABE Paper $97-$ 7024, 1997.
[81] Saad, Y., and Schultz, M., "GMRES: A Generalized Minimum Residual Algorithm for Solving Nonsymmetric Linear Systems," SIAM Journal of Scientific and Statistical Computing, Vol. 7, No. 3, 1986, pp. 856-869.

[82] “GASP Users Manual,” TR-3, Aerosoft, Blacksburg, VA, 1996.

[83] Huebner, L. D., and Tatum, K. E., "CFD Code Calibration and InletFairing Effects on a 3D Hypersonic Powered-Simulation Model," AIAA Paper 1993-3041, 1993.

[84] Huebner, L. D., and Tatum, K. E., "Computational and Experimental Aftbody Flow Fields for Hypersonic, Airbreathing Configurations with Scramjet Exhaust Flow Simulation,” AIAA Paper 1991-1709, 1991.

[85] Srinivasan, S., Bittner, R., and Bobskill, G., "Summary of GASP Code Application and Evaluation Effort for Scramjet Combustor Flowfields," AIAA Paper 1993-1973, 1993.

[86] Kumar, A., Gnoffo, P. A., Moss, J. N., and Drummond, J. P., "Advances in Computational Capabilities for Hypersonic Flows," AGARD Proceedings on Future Aerospace Technology in Service to the Alliance, AGARD Paper C-13, 1997.

[87] Spalart, P., and Allmaras, S., "A One-Equation Turbulence Model for Aerodynamic Flows," AIAA Paper 1992-0439, 1992.

[88] Wilcox, D. W., "Wall Matching, A Rational Alternative to Wall Functions," AIAA Paper 1989-0611, 1989

[89] Menter, F. R., "Zonal Two Equation $k-\omega$ Models for Aerodynamic Flows," AIAA Paper 1993-2906, 1993.

[90] Menter, F. R., "Improved Two-Equation $k-\omega$ Turbulence Models for Aerodynamic Flows," NASA TM-103975, 1992.

[91] Abid, R., "Evaluation of Two-Equation Turbulence Models for Predicting Transitional Flows," International Journal of Engineering Science, Vol. 31, No. 6, 1993, pp. 831-840. doi:10.1016/0020-7225(93)90096-D

[92] Abid, R., Morrison, J. H., Gatski, T. B., and Speziale, C. G., "Prediction of Complex Aerodynamic Flows with Explicit Algebraic Stress Models," AIAA Paper 1996-0565, 1996.

[93] Adumitroaie, V., Colucci, P., Taulbee, D., and Givi, P., "LES, DNS, and RANS for the Analysis of High-Speed Turbulent Reacting Flows," NASA Rept. NAG-1-1122, 1994.

[94] Girimaji, S. S., "Assumed Beta-pdf Model for Turbulent Mixing: Validation and Extension to Multiple Scalar Mixing," Combustion Science and Technology, Vol. 78, 1991, pp. 177-196. doi:10.1080/00102209108951748

[95] Gaffney, R. L., White, J. A., Girimaji, S. S., and Drummond, J. P., "Modeling Temperature and Species Fluctuations in Turbulent, Reacting Flow," Computer Systems Science and Engineering, Vol. 5, No. 2, 1994, pp. 117-133. doi:10.1016/0956-0521(94)90044-2

[96] Srinivasan, S., "Numerical Simulation of Turbulent Flow Past a Flat Plate," NASA Langley Research Center, HNAG Rept. 95-2-057, 1995

[97] Baurle, R. A., Fuller, R. P., White, J. A., Chen, T. H., Gruber, M. R., and Nejad, A. S., "An Investigation of Advanced Fuel Injection Schemes for Scramjet Combustion," AIAA Paper 1998-0937, 1998.

[98] White, J. A., and Morrison, J. H., "A Pseudo-Temporal Multi-Grid Relaxation Scheme for Solving the Parabolized Navier-Stokes Equations," AIAA Paper 1999-3360, 1999.

[99] van Leer, B., "Toward the Ultimate Conservative Difference Scheme, V. A Second Order Sequel to Godunov's Method," Journal of Computational Physics, Vol. 32, No. 1, 1979, pp. 101-136. doi:10.1016/0021-9991(79)90145-1

[100] Edwards, J. R., "A Low Diffusion Flux-Splitting Scheme for NavierStokes Calculations," Computers and Fluids Journal, Vol. 26, No. 6, 1997, pp. 635-659. doi:10.1016/S0045-7930(97)00014-5

[101] Litton, D. K., Edwards, J. R., and White, J. A., "Algorithmic Enhancements to the VULCAN Navier-Stokes Solver," AIAA Paper 2003-3979, 2003

[102] Baurle, R. A., "Modeling of High Speed Reacting Flows: Established Practices and Future Challenges," AIAA Paper 20040267, 2004.

[103] Baurle, R. A., Tam, C. J., Edwards, J. R., and Hassan, H. A., "Hybrid Simulation Approach for Cavity Flows: Blending, Algorithm, and Boundary Treatment Issues," AIAA Journal, Vol. 41, No. 8, 2003 , pp. $1463-1480$ doi:10.2514/2.2129

[104] Batten, P., Goldberg, U., and Chakravarthy, S., "Sub-Grid Turbulence Modeling for Unsteady Flow with Acoustic Resonance," AIAA Paper 2000-0473, 2000

[105] Batten, P., Goldberg, U., and Chakravarthy, S., "LNS—An Approach Towards Embedded LES," AIAA Paper 2002-0427, 2002. 
[106] Spalart, P. R., Jou, W.-H., Strelets, M., and Allmaras, S. R., “Comments on the Feasibility of LES for Wings, and on a Hybrid RANS/LES Approach," Advances in DNS/LES: Proceedings of the First Air Force Office of Scientific Research International Conference on DNS/LES, Greyden Press, Columbus, OH, 1997, pp. 137-148.

[107] Strelets, M., "Detached Eddy Simulation of Massively Separated Flows," AIAA Paper 2001-0879, 2001.

[108] Baurle, R. A., Tam, C. J., Edwards, J. R., and Hassan, H. A., "An Assessment of Boundary Treatment and Algorithm Issues on Hybrid RANS/LES Solution Strategies," AIAA Paper 2001-2562, 2001.

[109] Baurle, R. A., and Edwards, J. R., "Hybrid Reynolds-Averaged/LargeEddy Simulations of a Coaxial Supersonic Free-Jet Experiment," AIAA Paper 2009-0129, 2009.

[110] Baurle, R. A., and Edwards, J. R., "Hybrid Reynolds-Averaged/LargeEddy Simulations of a Coaxial Supersonic Freejet Experiment," AIAA Journal, Vol. 48, No. 3, 2010, pp. 551-571. doi:10.2514/1.43771

[111] Fan, T. C., Tian, M., Edwards, J. R., Hassan, H. A., and Baurle, R. A., "Validation of a Hybrid Reynolds-Averaged/Large-Eddy Simulation Method for Simulating Cavity Flameholder Configurations," AIAA Paper 2001-2929, 2001.

[112] Fan, T. C., Xiao, X., Edwards, J. R., Hassan, H. A., and Baurle, R. A., "Hybrid LES/RANS Simulation of a Shock Wave/Boundary Layer Interaction," AIAA Paper 2002-0431, 2002.

[113] Xiao, X., Edwards, J. R., and Hassan, H. A., "Inflow Boundary Conditions for Hybrid Large Eddy/Reynolds Averaged Navier-Stokes Simulations," AIAA Journal, Vol. 41, No. 8, 2003, pp. 2179-2193. doi: $10.2514 / 2.2130$

[114] Fan, C. C., Xiao, X., Edwards, J. R., and Hassan, H. A., "Hybrid Large-Eddy/Reynolds-Averaged Navier-Stokes Simulations of Shock-Separated Flows," Journal of Spacecraft and Rockets, Vol. 41, No. 6, 2004, pp. 2179-2193. doi: $10.2514 / 1.3735$

[115] Choi, J. I., Edwards, J. R., and Baurle, R. A., "Compressible Boundary Layer Predictions at High Reynolds Number Using Hybrid LES/ RANS Methods," AIAA Journal, Vol. 47, No. 9, 2009, pp. 2179-2193. doi: $10.2514 / 1.41598$

[116] Boles, J. A., Choi, J. I., Edwards, J. R., and Baurle, R. A., "Simulations of High-Speed Internal Flows Using LES/RANS Models," AIAA Paper 2009-1324, 2009.

[117] Boles, J. A., Edwards, J. R., and Baurle, R. A., "Large-Eddy/ReynoldsAveraged Navier-Stokes Simulations of Sonic Injection into Mach 2 Crossflow," AIAA Journal, Vol. 48, No. 7, 2010, pp. 1444-1456. doi:10.2514/1.J050066

[118] Gieseking, D. A., Choi, J. I., Edwards, J. R., and Hassan, A. H., "Simulation of Shock/Boundary Layer Interactions Using Improved LES/RANS Models," AIAA Paper 2010-0111, 2010.

[119] Edwards, J. R., Boles, J. A., and Baurle, R. A., "LES/RANS Simulation of a Supersonic Reacting Wall Jet," AIAA Paper 2010-0370, 2010.

[120] Gieseking, D. A., and Edwards, J. R., "Simulations of a Mach 3 Compression-Ramp Interaction Using LES/RANS Models," AIAA Paper 2011-0726, 2011.

[121] Ziberter, I. A., and Edwards, J. R., "LES/RANS Simulations of High-Speed Mixing Processes," AIAA Paper 2011-3423, 2011.

[122] Peterson, D. M., Candler, G. V., and Drayna, T. W., "Detached Eddy Simulation of a Generic Scramjet Inlet and Combustor," AIAA Paper 2009-0130, 2009.

[123] Peterson, D. M., and Candler, G. V., "Hybrid Reynolds-Averaged and Large-Eddy Simulation of Normal Injection into a Supersonic Crossflow," AIAA Journal, Vol. 26, No. 3, 2010, pp. 533-544.

[124] Peterson, D. M., and Candler, G. V., "Supersonic Combustor Fuel Injection Simulations Using a Hybrid RANS/LES Approach," AIAA Paper 2010-0411, 2010.

[125] Barnhardt, M., and Candler, G. V., "CFD Analysis of CUBRC Base Flow Experiments," AIAA Paper 2010-1250, 2010

[126] Tylczak, E. B., Peterson, D. M., and Candler, G. V., "Hybrid RANS/ LES Simulation of Transverse Jet in Supersonic Crossflow with Laser Energy Deposition," AIAA Paper 2010-4856, 2010.

[127] Peterson, D. M., and Candler, G. V., "Simulations of Mixing for Normal and Low-Angled Injection into Supersonic Crossflow," AIAA Journal, Vol. 49, No. 12, 2011, pp. 2792-2804. doi:10.2514/1.J051193

[128] Peterson, D. M., Tylczak, E. B., and Candler, G. V., "Hybrid ReynoldsAveraged and Large-Eddy Simulation of Scramjet Fuel Injection," AIAA Paper 2011-2344, 2011.

[129] Tylczak, E. B., Peterson, D. M., and Candler, G. V., "Hybrid RANS/ LES Simulation of Injection and Mixing in the CUBRC Combustion Duct," AIAA Paper 2011-3216, 2011.
[130] Cutler, A. D., Diskin, G. S., Drummond, J. P., and White, J. A., "Supersonic Coaxial Jet Experiment for Computational Fluid Dynamics Code Validation," AIAA Journal, Vol. 44, No. 3, 2006 pp. $585-592$. doi: $10.2514 / 1.5781$

[131] Clifton, C. W., and Cutler, A. D., "A Supersonic Argon/Air Coaxial Jet Experiment for Computational Fluid Dynamics Code Validation," NASA CR-214866, 2007.

[132] Miles, R. B., Grinstead, J., Kohl, R. H., and Diskin, G. S., "The RELIEF Flow Tagging Technique and Its Application in Engine Testing Facilities and for Helium-Air Mixing Studies," Measurement Science and Technology, Vol. 11, No. 9, 2000, pp. 1272-1281. doi:10.1088/0957-0233/11/9/304

[133] Bush, R. H., Power, G. D., and Towne, C. E., "WIND: The Production Flow Solver of the NPARC Alliance," AIAA Paper 1998-0935, 1998

[134] Georgiadis, N. J., Yoder, D. A., and DeBonis, J. R., "A Comparison of Three Navier-Stokes Solvers for Exhaust Nozzle Flowfields," AIAA Paper 1999-0748, 1999.

[135] Nelson, C. C., and Power, G. D., "CHSSI Project CFD-7: The NPARC Alliance Flow Simulation System," AIAA Paper 2001-0594, 2001.

[136] MacLean, M., and Holden, M., "Validation and Comparison of WIND and DPLR Results for Hypersonic, Laminar Problems," AIAA Paper 2004-0529, 2004

[137] Nelson, C. C., "An Overview of the NPARC Alliance's WIND-US Flow Solver," AIAA Paper 2010-0027, 2010.

[138] Toro, E. F., Spruce, M., and Speares, W., "Restoration of the Contact Surface in the HLL-Riemann Solver," Shock Waves, Vol. 4, No. 1, 1994, pp. 25-34. doi:10.1007/BF01414629

[139] Einfeldt, B., "On Godunov-Type Methods for Gas Dynamics," SIAM Journal of Numerical Analysis, Vol. 25, No. 2, 1988, pp. 294-318. doi:10.1137/0725021

[140] Rusanov, V. V., "Calculation of Interaction of Non-Steady Shock Waves with Obstacles," Journal of Computation in Mathematics and Physics USSR, Vol. 1, 1961, pp. 261-279.

[141] MacCormack, R. W., "Interactive Modified Approximate Factorization," Computers and Fluids, Vol. 30, Nos. 7-8, 2001, pp. 917-925.

[142] Pope, S. B., "PDF Methods for Turbulent Reactive Flows," Progress in Energy and Combustion Science, Vol. 11, No. 2, 1985, pp. 119-192. doi:10.1016/0360-1285(85)90002-4

[143] Pope, S. B., "PDF Methods for Combustion in High-Speed Turbulent Flows," NASA CR-199357, 1995.

[144] Welton, W. C., and Pope, S. B., "A PDF-Based Particle Method for Compressible Turbulent Flows," AIAA Paper 1995-0804, 1995.

[145] Delarue, B. J., and Pope, S. B., "Application of PDF Methods to Compressible Turbulent Flows," Physics of Fluids A, Vol. 9, No. 9, 1997, pp. 2704-2715. doi: $10.1063 / 1.869382$

[146] Delarue, B. J., and Pope, S. B.. "Calculations of Subsonic and Supersonic Turbulent Reacting Mixing Layers Using Probability Density Function Methods," Physics of Fluids, Vol. 10, No. 2, 1998 , pp. $487-498$ doi: $10.1063 / 1.869536$

[147] Hsu, A. T., Tsai, Y. L. P., and Raju, M. S., "A PDF Approach for Compressible Turbulent Reacting Flows," AIAA Paper 1993-0087, 1993

[148] Hsu, A. T., and Raju, M. S., "Application of a PDF Method to Compressible Turbulent Reacting Flows," AIAA Paper 1994-0781, 1994.

[149] Norris, A. T., and Hsu, A. T., "Comparison of PDF and Moment Closure Methods in the Modeling of Turbulent Reacting Flows," AIAA Paper 1994-3356, 1994.

[150] Baurle, R. A., and Girimaji, S. S., "An Assumed PDF TurbulenceChemistry Closure with Temperature-Composition Correlations," AIAA Paper 1999-0928, 1999.

[151] Kerstein, A. R., "A Linear Eddy Model of Turbulent Scalar Transport and Mixing," Combustion Science and Technology, Vol. 60, Nos. 4-6, 1988, pp. 391-421 doi:10.1080/00102208808923995

[152] Kerstein, A. R., "One-Dimensional Turbulence: Model Formulation and Application to Homogeneous Turbulence, Shear Flows, and Buoyant Stratified Flows," Journal of Fluid Mechanics, Vol. 392, Aug. 1999, pp. 277-334 doi:10.1017/S0022112099005376

[153] Nik, M. B., Mohebbi, M., Sheikhi, M. R. H., and Givi, P., "Progress in Large Eddy Simulation of High-Speed Turbulent Mixing and Reaction," AIAA Paper 2009-0133, 2009.

[154] Givi, P., "Filtered Density Function for Subgrid Scale Modeling of Turbulent Combustion,” AIAA Journal, Vol. 44, No. 1, 2006, pp. 16-23. doi:10.2514/1.15514 
[155] Poinsot, T., and Veynante, D., Theoretical and Numerical Combustion, 2nd ed., Edwards, Philadelphia, PA, 2000.

[156] Ansari, N., Jaberi, F. A., Sheikhi, M. R. H., and Givi, P., "Filtered Density Function as a Modern CFD Tool," Engineering Applications of Computational Fluid Dynamics, edited by Al-Baghdadi, M. A. R. S., Vol. 1, International Energy and Environment Foundation, Al-Najaf, Iraq, 2011, pp. 1-22.

[157] Drozda, T. G., Sheikhi, M. R. H., Madnia, C. K., and Givi, P., "Developments in Formulation and Application of the Filtered Density Function," Flow, Turbulence and Combustion, Vol. 78, No. 1, 2007, pp. 35-67. doi:10.1007/s10494-006-9052-4

[158] Givi, P., "Model Free Simulations of Turbulent Reacting Flows," Progress in Energy and Combustion Science, Vol. 15, No. 1, 1989, pp. 1-107. doi:10.1016/0360-1285(89)90006-3

[159] Pope, S. B., "Computations of Turbulent Combustion: Progress and Challenges," Proceedings of the Combustion Institute, Vol. 23, 1990, pp. 591-612.

[160] Givi, P., Sheikhi, M. R. J., Drozda, T. G., and Madnia, C. K., "Invited Review: Reliable and Affordable Simulation of Turbulent Combustion," AIAA Paper 2007-0190, 2007.

[161] Yilmaz, S. L., Nik, M. B., Givi, P., and Strakey, P. A., "Scalar Filtered Density Function for Large Eddy Simulation of a Bunsen Burner," Journal of Propulsion and Power, Vol. 26, No. 1, 2010, pp. 84-93. doi: $10.2514 / 1.44600$

[162] Nik, M. B., Yilmaz, S. L., Givi, P., Sheikhi, M. R. H., and Pope, S. B., "Simulation of Sandia Flame D Using Velocity-Scalar Filtered Density Function," AIAA Journal, Vol. 48, No. 7, 2010, pp. 1513-1522. doi:10.2514/1.J050154

[163] Ansari, N., Goldin, G. M., Pisciuneri, P. H., Nik, M. B., Strakey, P. A., and Givi, P., "FDF Simulation of Swirling Reacting Flows on Unstructured Meshes," AIAA Paper 2011-0109, 2011.

[164] Sheikhi, M. R. H., Givi, P., and Pope, S. B., "Velocity-Scalar Filtered Mass Density Function for Large Eddy Simulation of Turbulent Reacting Flows," Physics of Fluids, Vol. 19, No. 9, 2007, pp. 1-21. doi:10.1063/1.2768953

[165] Sheikhi, M. R. H., Givi, P., and Pope, S. B., "Frequency-VelocityScalar Filtered Mass Density Function for Large Eddy Simulation of
Turbulent Flows," Physics of Fluids, Vol. 21, No. 7, 2009, pp. 1-14. doi:10.1063/1.3153907

[166] Yilmaz, S. L., Ansari, N., Pisciuneri, P. H., Nik, M. B., Otis, C. C., and Givi, P., "Advances in FDF Modeling and Simulation," AIAA Paper 2011-5918, 2011

[167] Banaeizadeh, A., Li, Z., and Jaberi, F. A., "Compressible Scalar Filtered Mass Density Function Model for High-Speed Turbulent Flows," AIAA Journal, Vol. 49, No. 10, 2011, pp. 2130-2143. doi:10.2514/1.J050779

[168] Banaeizadeh, A., Li, Z., and Jaberi, F. A., "Large-Eddy Simulations of Compressible Turbulent Reacting Flows," AIAA Paper 2010-0202, 2010

[169] Jaberi, F. A., "Large-Eddy Simulation of Turbulent Premixed Flames via Filtered Mass Density Function," AIAA Paper 1999-0199, 1999.

[170] Asghar, A., Jaberi, F. A., and Shih, T. I. P., "LES/FMDF of Turbulent Combustion in Complex Flow Systems," AIAA Paper 2007-1414, 2007.

[171] Banaeizadeh, A., Li, Z., and Jaberi, F. A., "Large-Eddy Simulation of Turbulent Combustion via Filtered Mass Density Function," AIAA Paper 2011-5745, 2011.

[172] Afshari, A., and Jaberi, F. A., "Large-Eddy Simulations of Turbulent Flows in an Axisymmetric Dump Combustor," AIAA Journal, Vol. 49 No. 10, 2011, pp. 2130-2143.

[173] Yu, J., Luo, L. S., and Girimaji, S. S., "Scalar Mixing and Chemical Reaction Simulations Using Lattice Boltzmann Method," International Journal of Computational Engineering Science, Vol. 3, No. 1, 2002, pp. 73-78 doi:10.1142/S1465876302000551

[174] Gould, R. D., Stevenson, W. H., and Thompson, H. D., "Investigation of Turbulent Transport in an Axisymmetric Sudden Expansion," AIAA Journal, Vol. 28, No. 2, 1990, pp. 276-283. doi: $10.2514 / 3.10385$

[175] Gould, R. D., Stevenson, W. H., and Thompson, H. D., "Simultaneous Velocity and Temperature Measurements in a Premixed Dump Combustor," Journal of Propulsion and Power, Vol. 10, No. 5, 1995, pp. 639-645. doi:10.2514/3.23774
P. Givi

Associate Editor 